\title{
SELF-EMPLOYMENT IN CHILE, LONG RUN TRENDS AND EDUCATION AND AGE STRUCTURES CHANGES
}

\author{
EMPLEO POR CUENTA PROPIA EN CHILE, TENDENCIAS DE LARGO \\ PLAZO Y CAMBIOS EN LA ESTRUCTURA EDUCACIONAL Y ETARIA
}

\author{
Esteban PUENTES* \\ Dante CONTRERAS** \\ Claudia SanhueZa***
}

\begin{abstract}
This paper studies long-term trends of self-employment in Chile. Self-employment is associated with poor job conditions, vulnerability, and instability or informal labor market. Contrary to what is expected, self-employment level does not respond to macroeconomic variables. Using forty-one cross sections of the longest Employment Survey available, we show that there is little correlation of the economic cycle with variations in self-employment. Cohort effects are also unimportant. In fact, age is the most important predictor of self-employment; older people are more likely to be self-employed. In addition, we performed a decomposition of changes in self-employment on changes in coefficients, which are a measure of the returns to individual characteristics, and on changes in characteristics. The results indicate that self-employment should have decreased given the changes in individual characteristics, but was prevented by changes in coefficients. We also find indirect evidence that these changes in parameters are not correlated with macroeconomic variables. Finally, the changes in individual characteristics, such as education and age, and changes in their coefficients account for most of the changes in self-employment.
\end{abstract}

Key words: informal employment, cohort analysis, oaxaca decomposition.

\section{Resumen}

Este trabajo estudia las tendencias de largo plazo del empleo por cuenta propia en Chile. El empleo por cuenta propia está asociado con pobres condiciones de trabajo, vulnerabilidad e inestabilidad o informalidad laboral. Contrario a lo que se espera, el nivel del empleo por cuenta propia no responde a variables macroeconómicas. Usando 41 cohortes transversales de la encuesta de empleo más extensa disponible mostramos que existe poca correlación entre los ciclos económicos y las variaciones del empleo por cuenta propia. Los efectos de cohorte tampoco son importantes. De hecho, la edad es el predictor más importante del empleo por cuenta propia; personas de mayor edad presentan

* University of Chicago. E-mail: epuentes@uchicago.edu

** University of Chile. E-mail: dcontrer@econ.uchile.cl

***Universidad Alberto Hurtado. E-mail: csanhuez@ ahurtado.cl 
una mayor probabilidad de ser autoempleados. Adicionalmente, realizamos una descomposición de cambios en empleo por cuenta propia en cambios en los coeficientes, los cuales son una medida de los retornos a las características individuales, y en cambios en características. Los resultados muestran que el empleo por cuenta propia debería haber disminuido debido a los cambios en las características individuales, pero esto fue compensado por cambios en los coeficientes. También encontramos evidencia indirecta que estos cambios en los parámetros no están correlacionados con variables macroeconómicas. Finalmente, los cambios en características individuales, tales como educación y edad, y cambios en sus respectivos coeficientes, explican la mayor parte de los cambios en el empleo por cuenta propia.

Palabras clave: empleo informal, análisis de cohortes, descomposición de oaxaca.

JEL Classification: C13, J23.

\section{INTRODUCTION}

This paper studies the evolution of self-employment in a developing country for an unusually long length of time, 1965 to 2006, during which several economic reforms occurred. Self-employment has been associated with poor job conditions, vulnerability, and instability. Self-employed individuals in developing countries have no social security, severance pay, minimum wage, or working condition standard. Moreover, they do not have access to vocational training.

Self-employment in the Chilean labor market on average represents $20 \%$ of the workforce for the whole period in Greater Santiago. Female self-employment shows a U shape trend, it decreased steadily from more than $22 \%$ in 1965 to $15 \%$ in 1998 and then rose afterwards reaching $19 \%$ in 2006. In contrast the male workforce shows no significant changes on self-employment. A small increase is observed from 1965 to 1988 and a drop after that. The evolution of self-employment seems to not be correlated with changes in economic activity and labor market regulations. One possible reason could be several employment programs implemented during the biggest economic crisis of the period, 1982 to 1984 . According to our data, these programs were very important and their presence could have mitigated the natural growth of self-employment for those years.

Chile has gone through several changes in labor market policies during the last fifty years. From regulated and protectionist legislation until 1973 to an unregulated labor market from 1973 to 1990 and to more protected legislation afterwards. In addition, the Chilean economy has exhibited a fluctuating economic growth, which affected unemployment which promoted the creation of emergency make-work programs in several years. These characteristics make Chile an interesting case to study the evolution of self-employment over a long period. Although self-employment levels and its determinants have been documented in several countries in the region, the evidence for Chile is limited ${ }^{1}$.

$\overline{1}$ One related work by Restrepo and Tokman (2005) groups a set of papers that evaluate the effects of the institutions on the Chilean labor market. 
In this report we employed two empirical strategies to investigate the main forces driving self-employment. First, we use micro simulation techniques to decompose changes in self-employment into two components: changes in characteristics and changes in parameters. Second, by using cohort analysis we decompose the self-employment rates for males and females in three factors: cohort effects, year effects and age affects.

The decomposition works in the following way, changes in self-employment are separated into two components: changes in workforce characteristics, such as education, age and household characteristics; and changes in the coefficients or propensities that those characteristics have on the probability of being a selfemployed worker. To model this probability we use two econometric methods: 1) a probit model between self-employment and the rest of the salaried workers, and 2) a multinomial probit for the choices between: self-employment, white collar workers and blue collar workers. Using the multinomial probit results, the effect of characteristics accounted for 14.6 percentage points and the effect of propensities accounted for -8 percentage points. This result implies that if coefficients would not had changed, the drop in self-employment would had been of 14.6 points. For males, during the entire period self-employment rose by 1.2 percentage points driven mostly by the propensities, 5.6 points, and counterbalance by characteristics, -5.2 points. These decomposition results show that the changes in characteristics should lead to a small drop on self-employment, however changes in propensities tend to counterbalance that effect, increasing it. When we compare the decomposition by decades, we found indirect evidence that going from high levels of regulation to no regulation in the labor markets, jointly with low economic growth situation that happened from 1965 to 1976, self-employment did not decrease, moreover, when combining high economic growth and medium market regulations, as in the 1986 to 1996 decade, selfemployment tends to decrease.

A cohort decomposition of self-employment was also estimated and the results confirm our previous findings. Year effects which are a measure of changes associated to the economic cycle are mostly not significant. For instance, for all the years with negative per-capita GDP growth, only in 1983 the year effect was significant, by decreasing self-employment for females and increasing it for males. For females, we find that for the period between 1985 to 1996, which presented high economic growth, year effects had a negative impact on self-employment. For the same period, we observe increasing labor market regulations that do not seem to increase self-employment.

Cohort effects, which are a measure of structural differences among generations, such as attitudes towards work and child care, are almost non-existing. Only age and education are the important factors. With and increase in age, there is an increase in the probability of being self-employed. This effect is higher for women than for men. Also lower education is correlated with a higher probability of self-employment.

Both methods show the little effect that macroeconomic variables had on self-employment. However, the changes in individual characteristics, which are the most important in the cohort decomposition, should produce a bigger drop in self-employment that did not occur because of changes in parameters. We do not know which factors affected those changes in parameters, but they do not seem to be correlated with economic activity or legislation reforms. 
The paper is organized as follows: the second section offers background information on the Chilean economy; the third section describes the data and the evolution of self-employment in Chile in several dimensions; the fourth section presents the cohort analysis. In the fifth section we show the decomposition results. Finally, the last section concludes.

\section{BACKGROUND INFORMATION ON CHILEAN LABOR MARKETS}

\subsection{Chilean labor market regulations ${ }^{2}$}

Chile has gone through several changes in labor market policies during the last fifty years. Table A2 presents a summary of those regulations and their implications on the cost of dismissal or labor rigidity. In addition, Figure 1 to Figure 3 present an index of job security, the evolution of the minimum wage, and an index of collective bargaining ${ }^{3}$. This information will help us to understand the evolution of the legal environment in the Chilean labor market. Montenegro and Pagés (2003) evaluate the effects of labor regulations in Chile and find negative effects on formal employment and, in addition, the regulations increase the probability of women and unskilled workers to be self-employed.

Before 1966 Chile had an unregulated labor market, with no legal requirements for dismissal expect for notice one month in advance. This latter characteristic has been kept constant over the years. However collective bargaining was introduced in 1931 with the labor code. Between 1960 and 1973 the unionization rate increased from $11 \%$ to $37 \%$ of total employed workers in 1973, reaching more than $50 \%$ in some sectors (Feres, 1997).

In 1966, the "ley de inamovilidad" (law of no-mobility) was introduced to impede employers from dismissing workers without just cause. From then until 1973, several laws were implemented in order to protect workers with job security provisions: high compensation, compensation by type of occupation, and labor supply restrictions by the existence of ID for type of occupations and special benefits for some unions. Firms had to pay compensation equal to one month's wage per year of work to all workers dismissed without just cause. Although the law considered economic needs of the firm as just cause and therefore workers dismissed would not qualify for severance pay; in practice,

2 This section presents an overview of Chilean labor market regulations. The analysis is based mainly on Edwards and Cox (2002), Mizala and Romaguera (2001), and Montenegro and Pagés (2003).

3 The measure of job security was taken from Montenegro and Pagés (2003). It computes the expected cost at the time a worker is hired of dismissing this worker in the future. The assumption is firms evaluate future dismissal costos based on current laws. Higher values of this variable indicate periods of relatively high job security, whereas lower values characterize periods in wich dismissals were less costly. The measure of bargaining power was constructed for Edwards and Cox (2000). This index reflects the degree of centralization of collective bargaining. This variable takes values from 1 (total decentralization) to 4 (total centralization). The use of this measure is based on the observation that union coverage tends to be larger in countries where collective bargaining is centralized. 
workers could appeal to courts and usually these dismissals were considered unjustified. In this latter case, the employer could choose between paying the mandatory compensation or reinstate the worker.

Likewise, collective bargaining for all types of unions was permitted. And, given that the affiliation was obligatory, the collective contract applied to all unionized workers. The regulation also allowed indefinite strikes with prohibition of replacement. Finally, in the private sector, wages were set through collective bargaining or directly with the employer, subject to the minimum wage. Indexation was generalized to the public and the private sector.

In 1973 the dictatorship violently changed the political situation and started a de facto liberalization of the labor market. Although during this period the protectionist norms were not modified, the strong degree of union activity repression permitted a real deregulation. This situation ended in massive increases of dismissals that used "economic needs by the firms" as firing cause.

The government also set by law the general increases of remunerations for the private and public sectors. Minimum wages were standardized and determined by the government without an established frequency. Since collective bargaining was prohibited, wages were rigidified. The decreasing inflation and indexation of salaries to passed inflation generated an increment of real wages between 1975 and 1982 .

The following period from 1978 to 1990 corresponds to the last years of the military regime. In this period the labor market is formally deregulated, via the "Labor Plan", since in 1979 collective bargaining, union activity and strike were re-established but in very different conditions than previously. Regarding dismissals, employers could dismiss workers without cause and there was no possibility of claim, but the compensation of a month per year of service remained. In 1981, this was limited to a maximum of 5 years. With the re-establishment of the collective bargaining, the politics of remunerations changed, with the mechanisms of market determined the salaries. Since 1982, the obligatory indexation of the private collective contracts was eliminated and the readjustment salaries stopped for the private sector. Edwards and Cox (2002) evaluate the effects of different labor market outcomes: wages, unemployment and employment. In particular, they find that effects were modest and that there was an increase of $2 \%$ on informal sector wages.

In 1990, after the return of democracy, a new labor reform further increased the cost of dismissal. In general terms, employment protection was increased and unions were given a slightly greater role in the collective bargaining process. The new democratic government, however, made an effort to maintain a "flexible" labor code. The new law considers dismissals motivated by the economic needs of the firm justified, but employers are still liable to pay compensation equal to one month's pay per year of work with a maximum amount of 11 months of pay. It is the responsibility of the firm to prove just cause. If such causality cannot be demonstrated, there is a 20 percent surcharge in the amount of compensation. Still, collective bargaining continues being highly decentralized, allowing for voluntary affiliation and unions for individual firms and groups of workers. The minimum wage was significantly increased and was differentiated by age group. 
FIGURE 1

JOB SECURITY INDEX (MONTENEGRO AND PAGÉS, 2003)

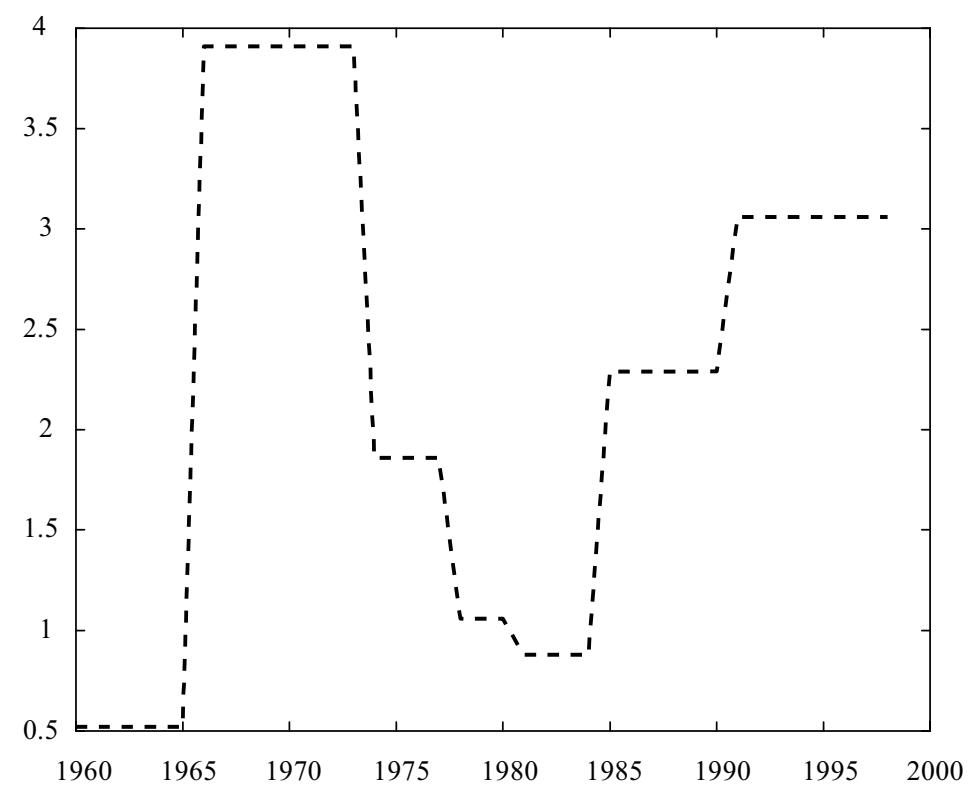

FIGURE 2

MINIMUM WAGE (MONTENEGRO AND PAGÉS, 2003)

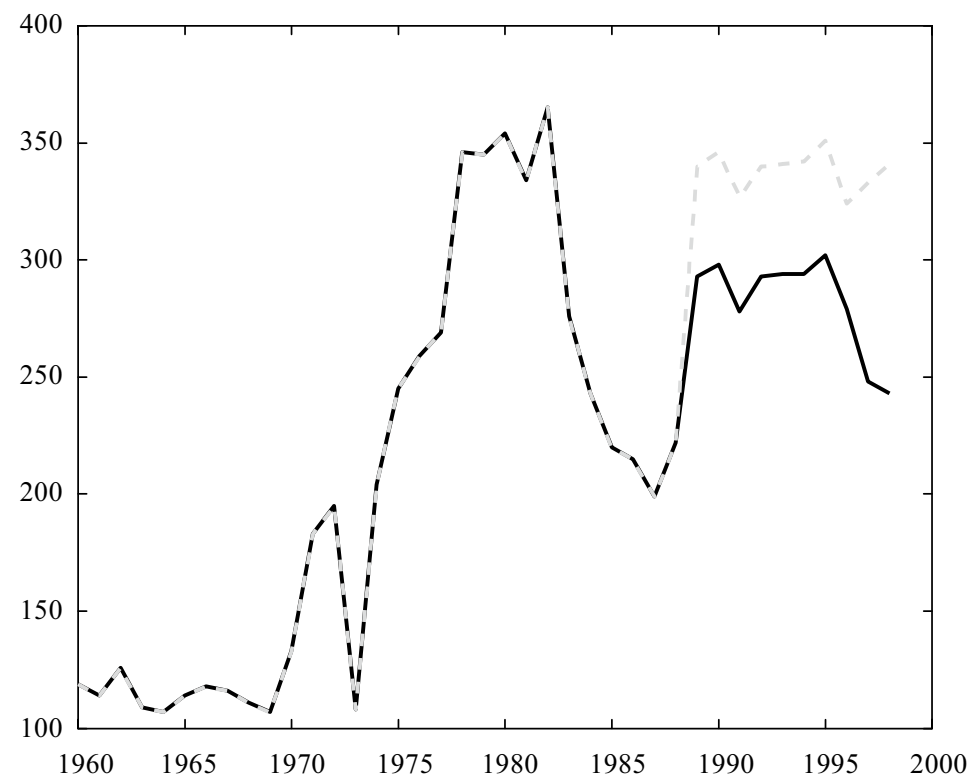


FIGURE 3

BARGAINING INDEX (MONTENEGRO AND PAGÉS, 2003)

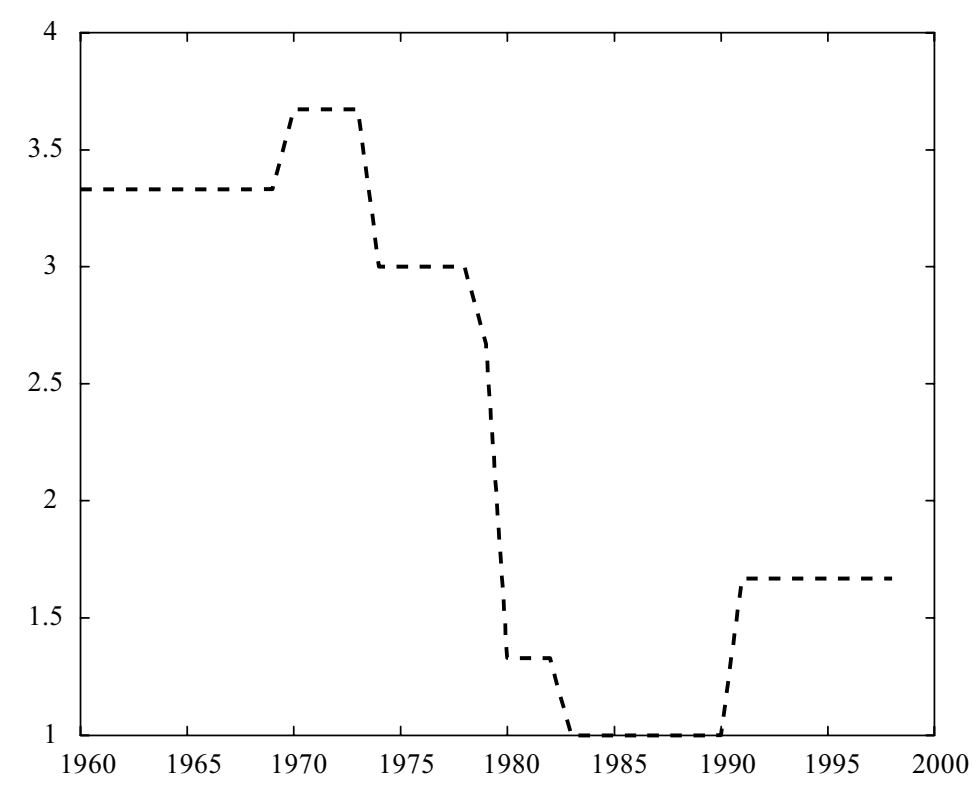

\section{DAta}

\subsection{Descriptive Statistics}

This section shows several characteristics of the self-employed sector in Chile. We take advantage of a long series of cross sectional surveys for Greater Santiago, known as the Employment and Unemployment Survey (EUS) and conducted every year by the Universidad de Chile.

We present results for the period between 1965 and 2006. This long range of data is particularly useful because it allows us to compare the effect of different macro and micro policies on self-employment. The uniformity of the questionnaire over time is of great benefit to study long term processes.

In this section we display figures that describe the Chilean labor market and their relationship with the informal sector. All the graphs are made separately for females and males, and we include individuals between 25 and 65 years old. The categories are the followings: employer, self-employed worker, white collar worker, blue collar worker and unpaid family worker.

Figure 4 shows the evolution of the different occupational categories for the period 1965-2006.

In the case of females, most of them are white collar workers, which shows a positive trend during the period. This is not surprising since the female labor 
force participation in Chile is mostly highly educated women. We also observe that the percentage of self-employment has significantly decreased compared to the proportion in the beginning of the period, especially the first 15 years. However, self employment have been increasing since 1998.

In the case of males, white collar and blue collar workers are the two main categories, with blue collar work being the most common. Self-employment is very stable during the period, with an small increase from 1965 to the end of the eighties. The percentage of employers is also very homogenous, moving around 8 to 10 percent. The stability of these categories is striking considering the numerous changes in the Chilean economy, with two important economic crisis, one in 1975-76 and the other in 1982-1984. There were also major changes in economic policy and democratic regimes. We can also appreciate that unpaid family workers are a very small proportion of the female occupational choice and almost non-existent for males.

Figure 5 simply displays the evolution of self-employment. Female selfemployment presents four distinctive periods: the first one from 1965 to 1976 , with high rates of self-employment, between 21 and 30 percent; then we observe a period of medium rates, from 1977 to 1981, with rates close to 20 percent; lastly from 1982 to 1998 we observe low rates, from 12 to 18 percent; and from 1998 until now the rate increases to $18 \%$.

For males the numbers are very stable with a positive slope from the beginning of the period until the late eighties and then slightly decreases afterwards.

FIGURE 4

PERCENTAGE OF WORKERS IN EACH CATEGORY
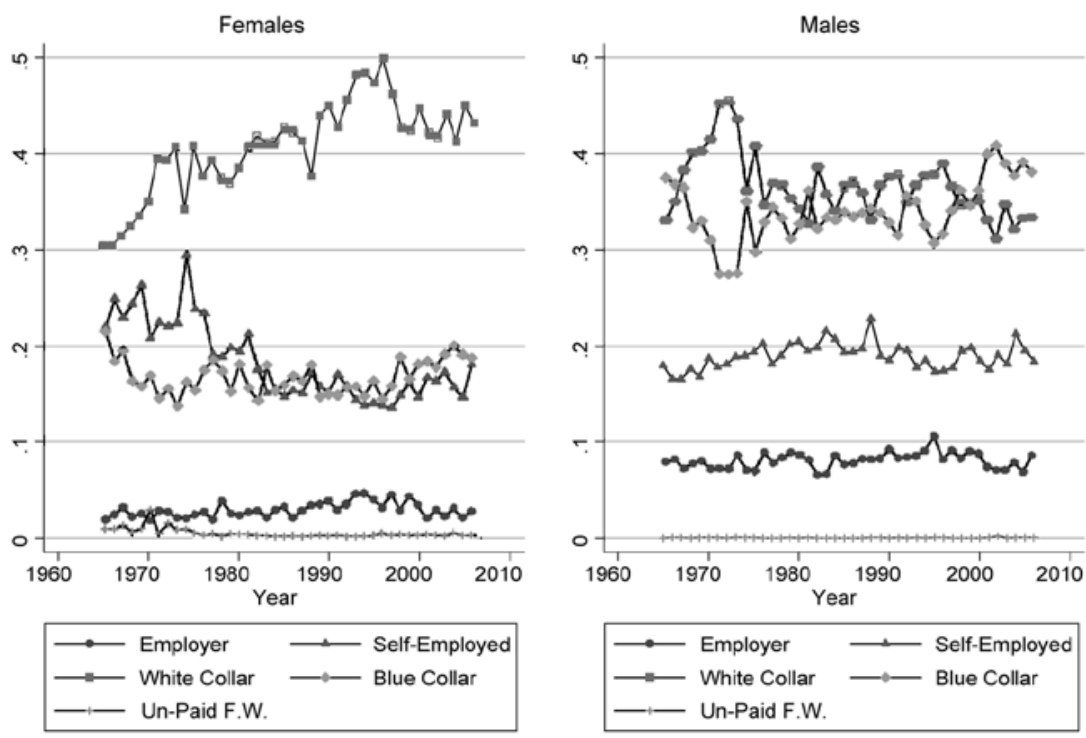

Source: Own estimates based on EUS. 
FIGURE 5

\section{PERCENTAGE OF SELF-EMPLOYMENT}

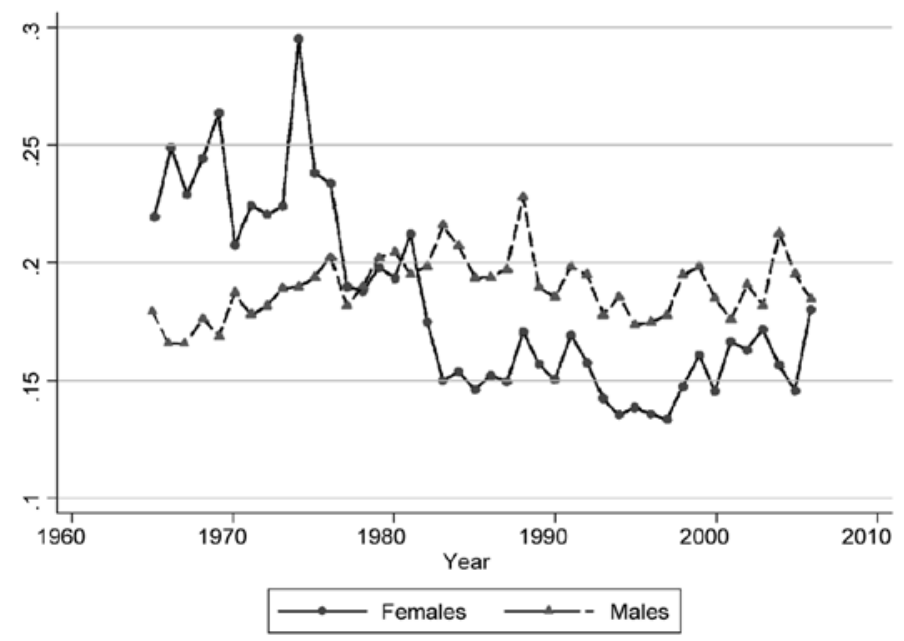

Figure 6 exhibits the average log hourly income by occupation. We note that for females and males the ordering is the same for the whole period. Not surprisingly, the order is highest to lowest income: employers, white collar workers, self-employed and finally blue collar workers.

FIGURE 6

MEAN LOG INCOME BY CATEGORY
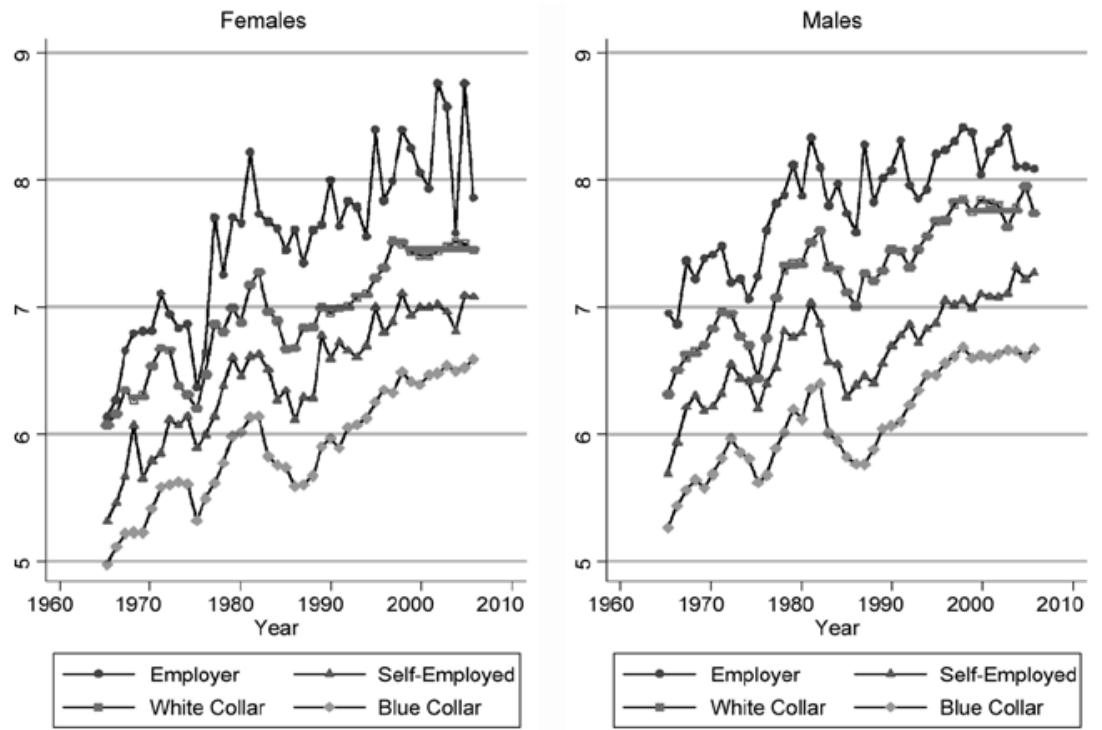

Source: Own estimates based on EUS. 
We decided not to include employers in the rest of the analysis ${ }^{4}$.

Figure 7 presents the log of the income ratios between self-employed workers and blue collar and white collar workers. Females have a smaller difference in income between the white collar and self-employed categories. The ratio between self-employed income and blue collar income is stable over time and similar for females and males.

FIGURE 7

LOG INCOME RATIOS
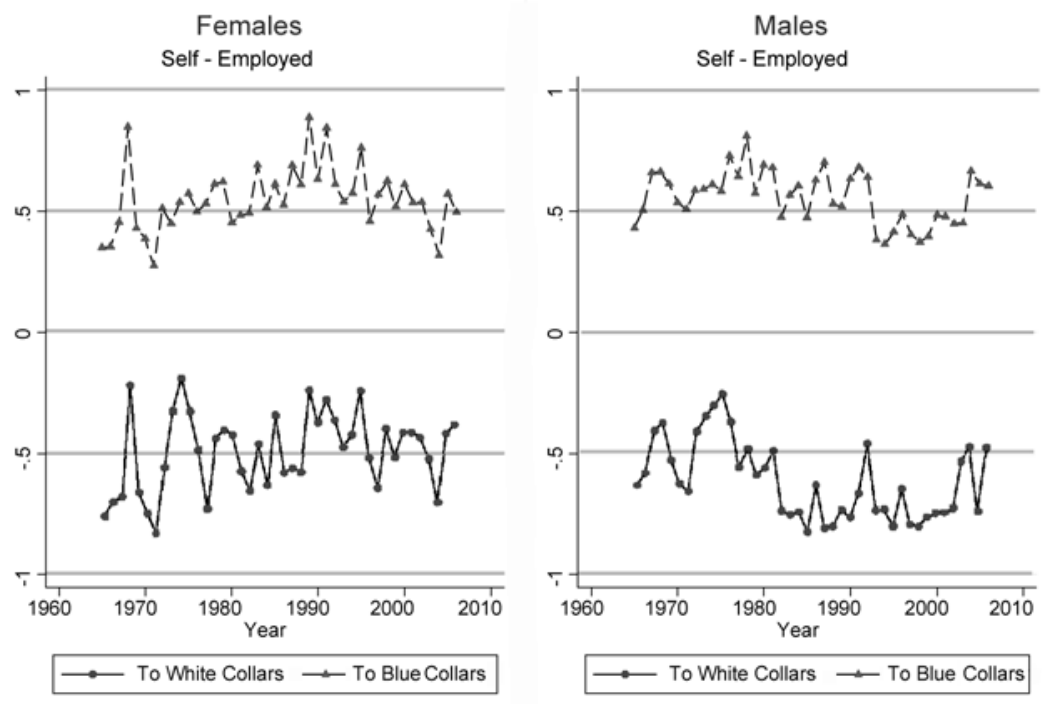

Source: Own estimates based on EUS

Figure 8 displays the income distribution for self-employed, blue collar and white collar workers for four different years ${ }^{5}$. We observe that the distributions are very similar over the years, with low levels and dispersion for blue collar and higher dispersion for white collar and self-employed workers. The graphs move to the right across time, showing the increase in income experienced in the Chilean labor market.

Education levels differ greatly by occupational category, for females and males; white collar workers are the most educated group, followed by selfemployed and blue collar workers. Nevertheless, the difference between these two categories is very small for females and has been decreasing steadily for males (see Figure 9).

4 Only a 3 percent of females are employers, this low percentage implies that very few observations are available, making most of the inference unreliable.

5 The years were chosen to divide the periods in an proporcional manner. 


\section{FIGURE 8}

\section{LOG WAGE DISTRIBUTION}

Females

1965
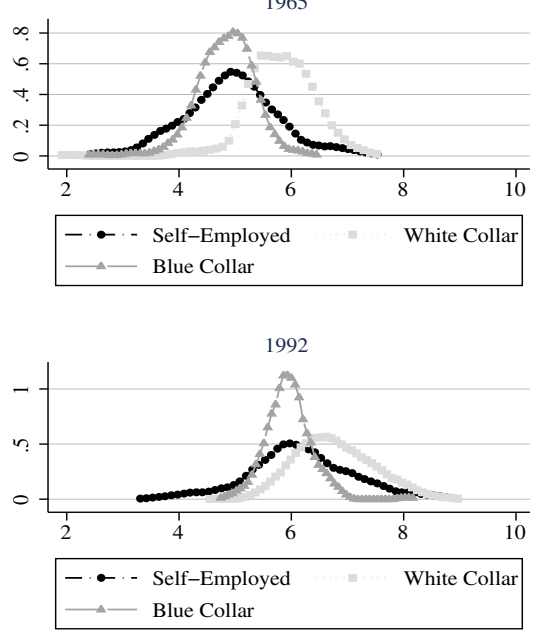

1979

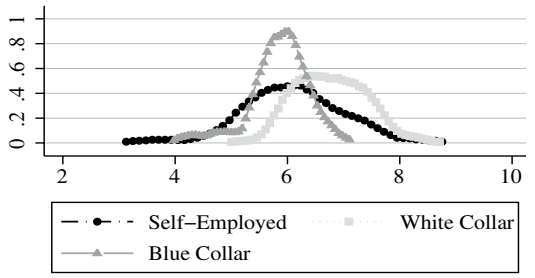

2006

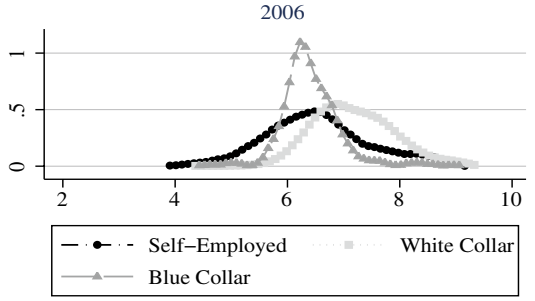

Source: Own estimates based on EUS.

Males

1965

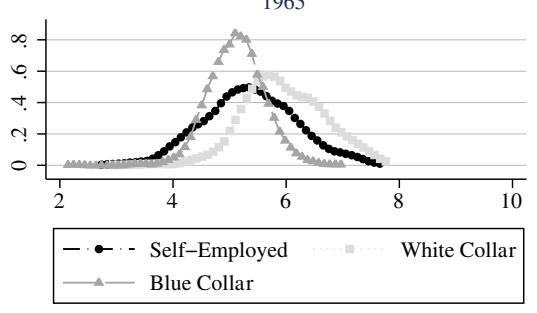

1992

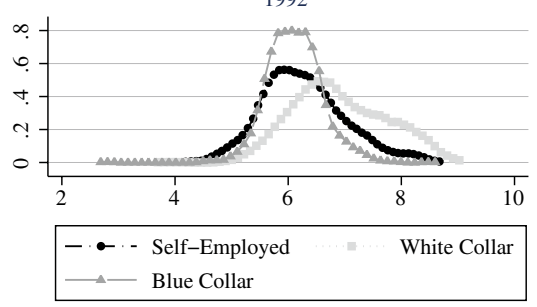

1979

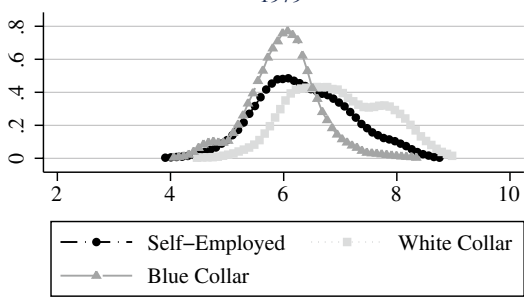

2006

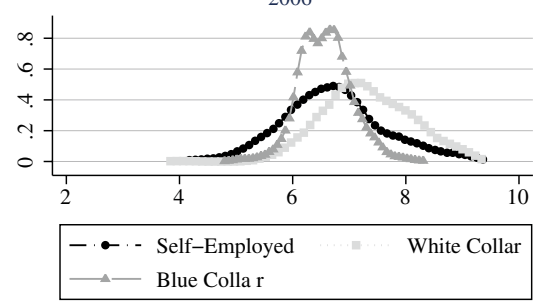

Source: Own estimates based on EUS. 
FIGURE 9

AVERAGE YEARS OF EDUCATION
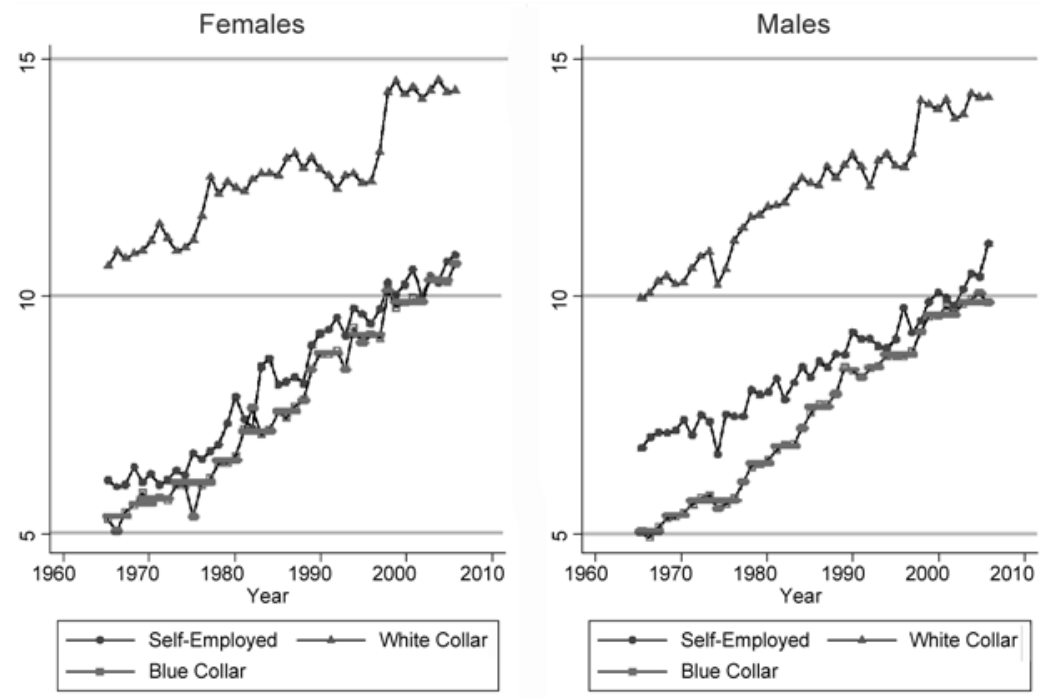

Source: Own estimates based on EUS.

One of the factors that must be taken into account when analyzing selfemployment is the presence of highly skilled individuals in this category, who choose to work by themselves because of the flexibility offered by this alternative. We should acknowledge this fact and separate this high skilled group. We calculate what proportion of self-employed workers have more than 12 years of education and more than 16 years of education ${ }^{6}$. The following graphs show that these proportions are very low, although they increase over time, which is part of the increasing trend in education observed in Chile. The evidence presented on Figure 10 indicates that self-employment tends to be an unskilled activity.

Figure 11 shows the average age for workers in each category, and the proportion of each category for different age groups.

There is a strong correlation between age and occupational choice for both females and males: the probability of becoming a self-employed increases with age.

For workers between 25 and 34 years old, self-employment is the smallest occupational category, for females and males. Moreover, for males between 35 and 44 self-employment is still the smallest category. For older groups, self-employment increases and for females between 55 and 65 years old, self-employment is the most common occupation for several years (see Figures 12 and 13).

Figure 14 presents the percentage of workers who work part-time in each occupational category. Self-employment has the highest shares of workers in part time jobs. This result demonstrates one of the characteristics of this occupa-

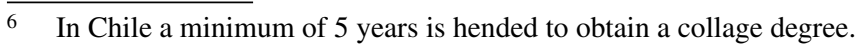


FIGURE 10

PERCENTAGE AS SELF-EMPLOYED
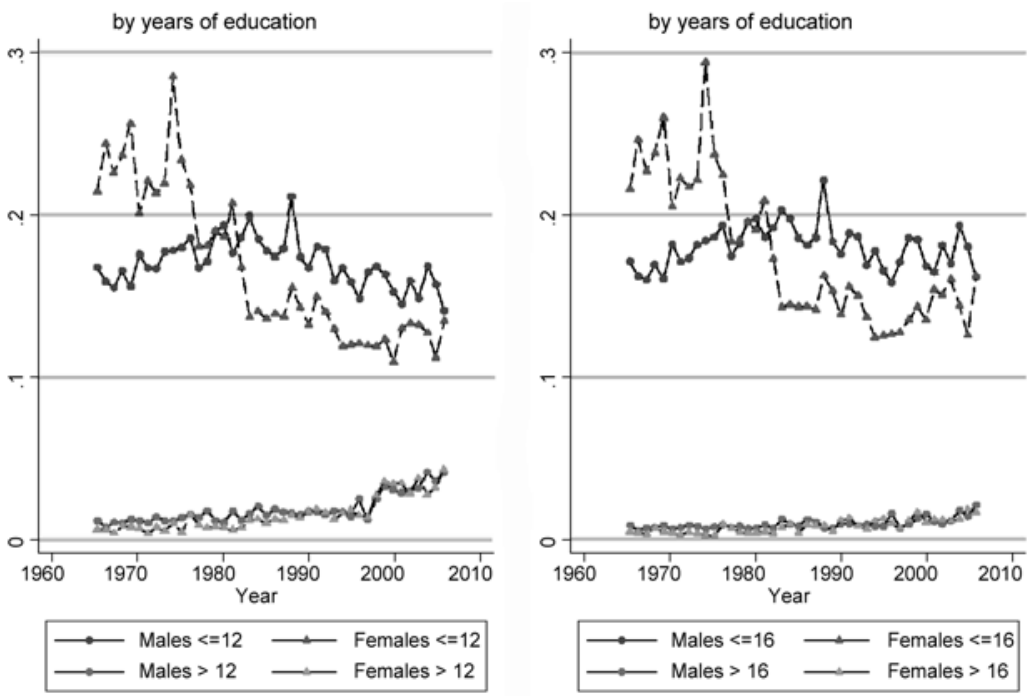

Source: Own estimates based on EUS.

FIGURE 11

AVERAGE AGE BY CATEGORY

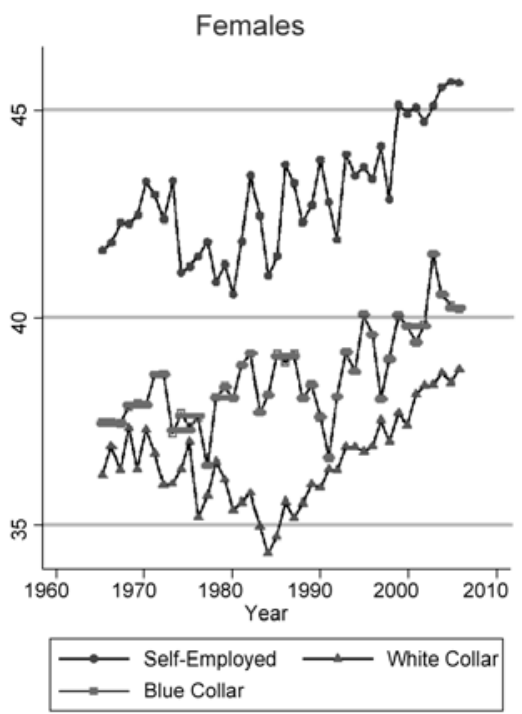

Males

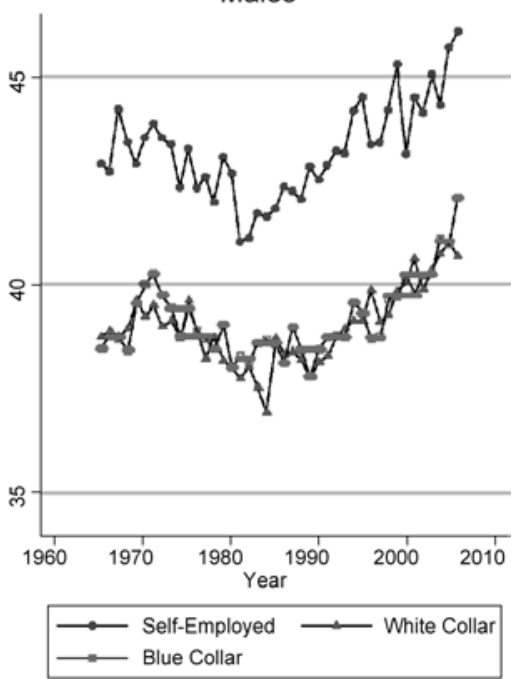

Source: Own estimates based on EUS. 
FIGURE 12

OCCUPATIONAL DISTRIBUTION BY AGE, FEMALES
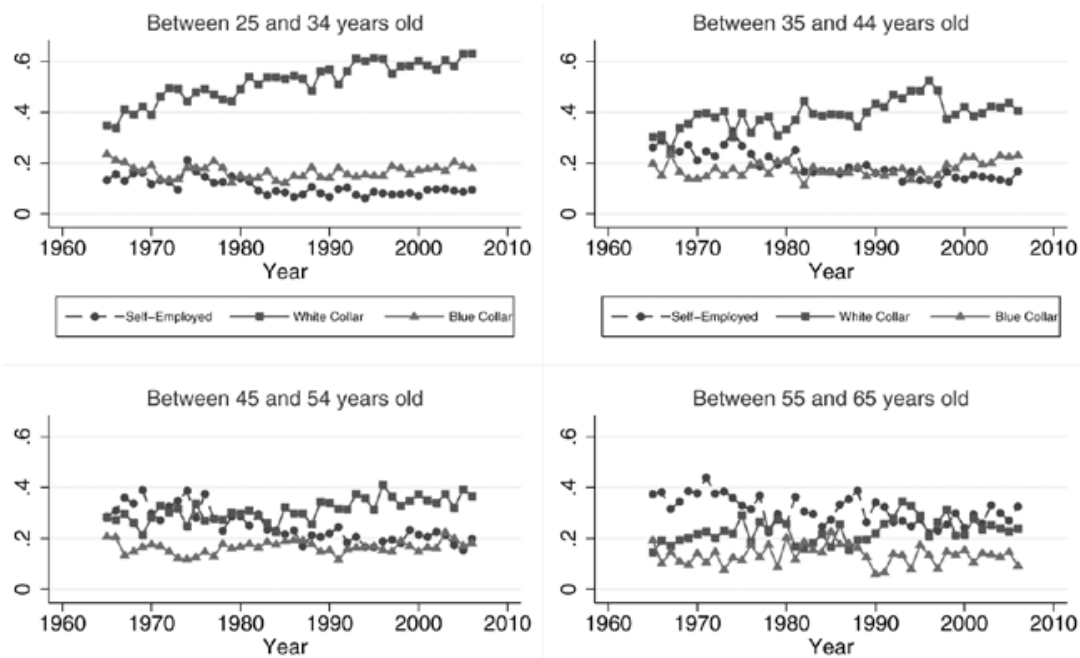

- - -Sell-Employed $\longrightarrow$ White Collar $\longrightarrow$ Blue Collar

- - -Selt-Employed $\longrightarrow$ while Collar $\longrightarrow$ Bive Collar

Source: Own estimates based on EUS.

FIGURE 13

OCCUPATIONAL DISTRIBUTION BY AGE, MALES
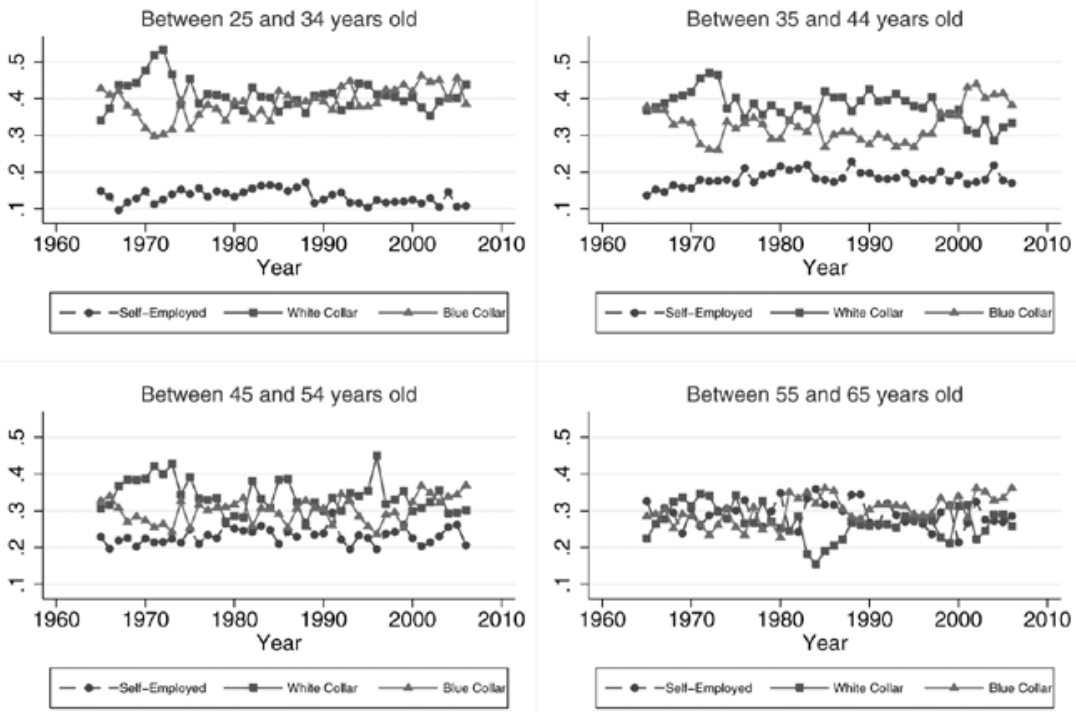

Source: Own estimates based on EUS. 
tion: the flexibility that offers to individuals. Nonetheless, it is still the case that this group lacks social protection. It could be the case that some people would be willing to work more as a self-employed or salaried worker but they are not able to do so, or is not profitable.

One of the unexpected events we found in the data is the increase in parttime work for blue collar workers during the early eighties. During this period Chile suffered an enormous economic crisis and one of the measures taken by the authorities was to create special employment plans, which appear to be captured in Figure 14. We also found an increase in public sector activity for blue collar workers for the same period which also is evidence of the presence of these emergency employment plans (Figure 17).

Figures 15 and 16 present the evolution of two important macroeconomic variables, which are useful to put in context some results found previously.

First we observe that the female participation rate increases especially since 1984, however, the most important changes in female self-employment occurred before that. This implies that the drop in self-employment in the late seventies and early eighties must be correlated with other variables. One of the possible hypothesis that we wanted to test is that there is an increase in self-employment when unemployment rises, since self-employment could function as alternative earnings, however it is difficult to find any correlation. One of the reasons for not finding this is that, in the beginning of the eighties, there is an increase in the proportion of blue collars in the public sector, shown in the next graph, due to special employment programs. These programs seem to employ most of the potential self-employed workers; nevertheless, during that period self-employment slightly increase in males.

FIGURE 14

PERCENTAGE WITH PARTIAL TIME
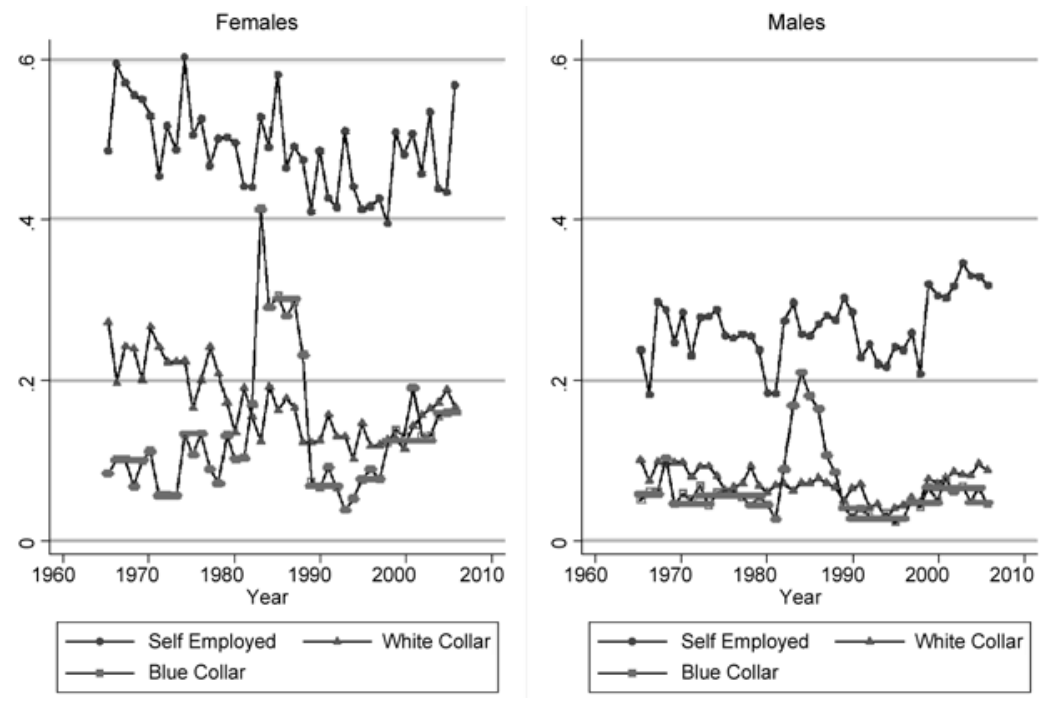

Source: Own estimates based on EUS. 
FIGURE 15

EVOLUTION OF LABOR VARIABLES FOR THE PERIOD
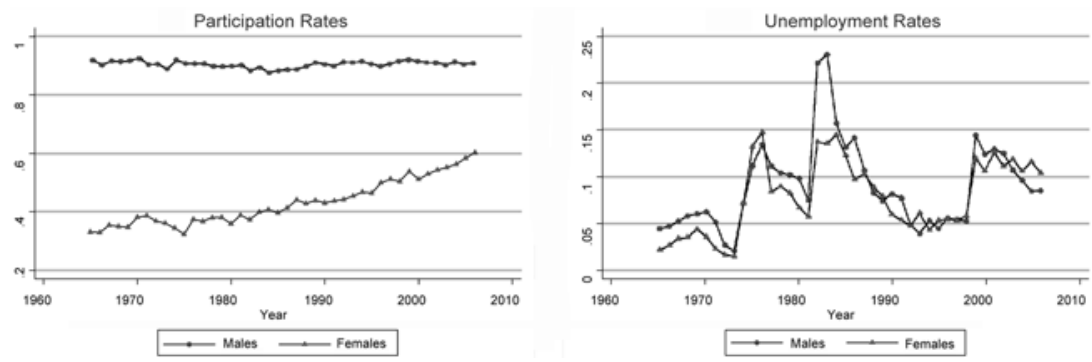

Source: Own estimates based on EUS.

FIGURE 16

COMPARING UNEMPLOYMENT AND SELF-EMPLOYMENT
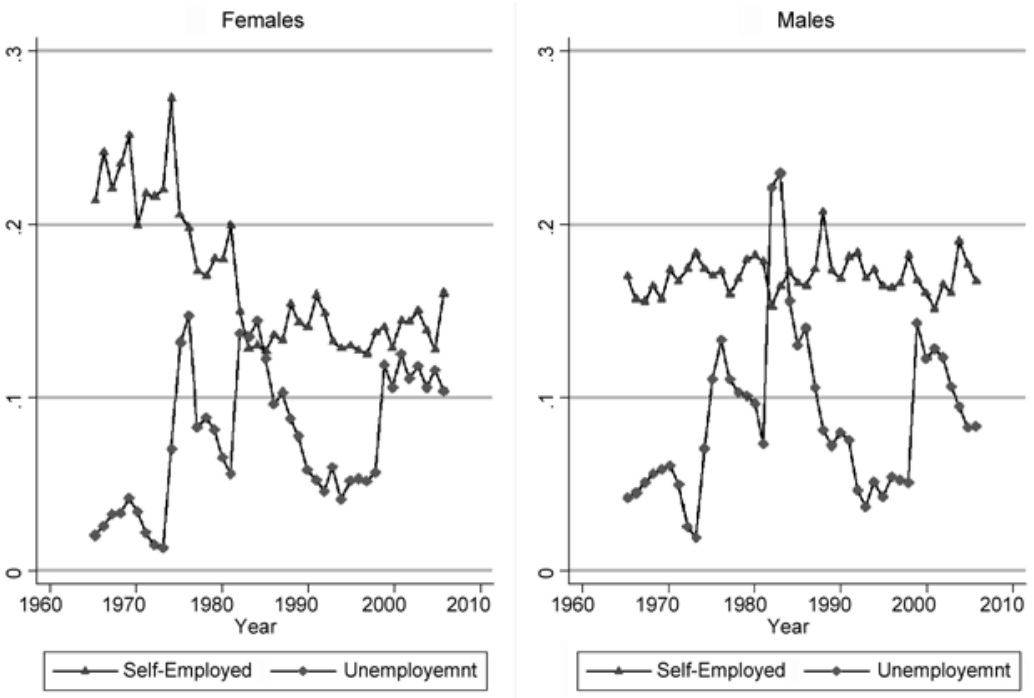

Source: Own estimates based on EUS.

Figure 17 shows the percentage of white collar and blue collar workers hired in the public sector. Besides the already noted growth of blue collar workers during the eighties crisis, we can observe a drop in white collar workers in the public sector during the whole period. Again, we could expect that a proportion of those workers who are leaving the public sector could become self-employed, however, it seems that they mainly continued as white collars in the private sector. 
FIGURE 17

PERCENTAGE IN THE PUBLIC SECTOR
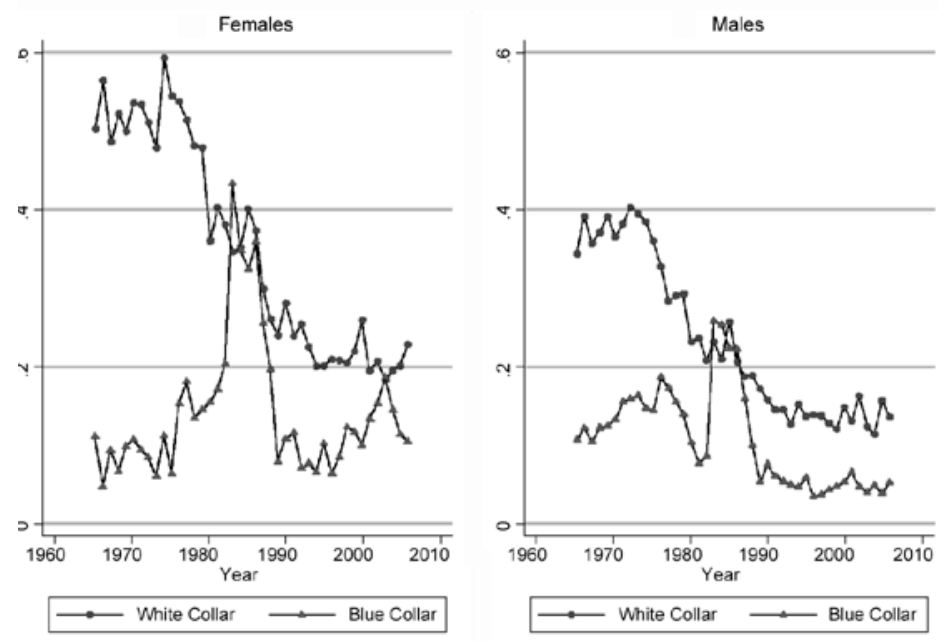

Source: Own estimates based on EUS.

\section{Cohort Estimation}

Using data from 1965 to $2006^{7}$, cohort, year, and age effect are estimated. The cohort effect measures how generations differ in their attitude towards selfemployment. For instance, new generations could favor self-employment given the flexibility that offers or new generations could love risk more than their parents and prefer the income uncertainty of self-employment. The age effect measures the life cycle, such as, when people get old it could be more difficult for them to find a salaried job, which force them to work as self-employment. The year effect measure mostly macroeconomic variables as GDP growth, but also institutional changes can be important.

In the estimation each individual was considered as an observation, instead of the traditional econometric approach which creates averages by cohorts and age groups. Using individual observations could have been problematic if the size of the surveys were different from year to year, but that was not an issue.

The estimation was a probit on the decision of becoming self-employed, instead of working as a salaried worker (white or blue collar worker).

The equation estimated was the following

$$
\operatorname{Pr}(\text { Self-Employed })=F(\text { Cohort, Age, Year, Education })
$$

The Deaton decomposition was used to avoid multicollinearity. The estimation were made separately for females and males. We have 39,753 observations for females and 84,169 for males. The following graphs show the results for the age effect for females and males.

7 The years before 1965 were not considered in the estimation due to the lack of information for educational variables in some years. 


\section{FIGURE 18}

\section{AGE EFFECT}
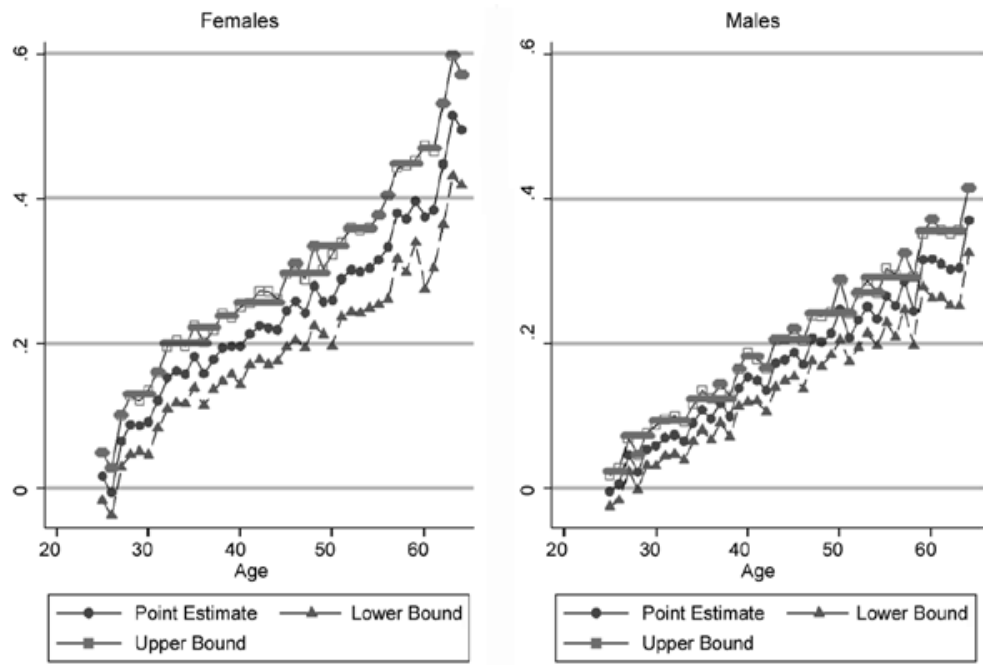

Source: Own estimates based on EUS.

We observe that older people have a higher probability of becoming selfemployed, for both females and males, but there is a stronger relationship for females. Almost all of the coefficient are significant (at a 5\%).

The next graphs show the year effects.

FIGURE 19

YEAR EFFECT
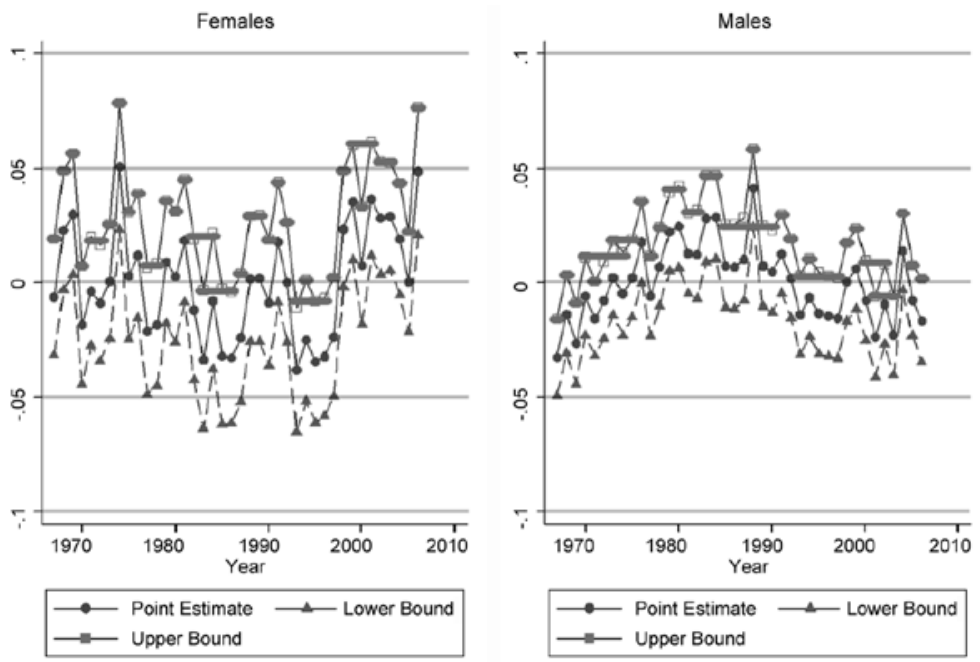

Source: Own estimates based on EUS. 
We observe that the coefficients are positive for females in the years: 1969 , 1974, 1999, 2002 to 2003 and 2006, and are negative for the following years: 1983, 1985, 1986, 1993, 1995 and 1996. When comparing these results with GDP growth (Table A1), we appreciate that most of the positive coefficients are correlated with low growth and the negative coefficients with high growth, this implying that female self-employment is, at some degree, negatively related with economic activity. We also find that, in contradiction with Montenegro and Pagés (2003), self-employment decreased for women in the early nineties when labor protection increased. However these differences could be influenced by our year effect being a mixture of several inputs. These include: economic growth, labor reforms, and political changes and explicitly introduce variables that account for labor regulations.

For males, the years with positive coefficients are: 1979, 1980, 1983, 1984 and 1988 and the years with negative coefficients are: 1967, 1969, 2001 and 2003. It seems that the crisis of the years 1982 and 1983 has an effect on selfemployment, however other episodes of high unemployment, such as 1975 and 1976, have no significant effect. Contrary to the findings for women, the results for males show that, when positive coefficients are found, GDP was growing and when negative coefficients are found, slower GDP growth occurred. These results remain as a puzzle for us since self-employment is generally believed to be negatively correlated with growth.

Figure 20 shows the cohort effects.

FIGURE 20

COHORT EFFECT
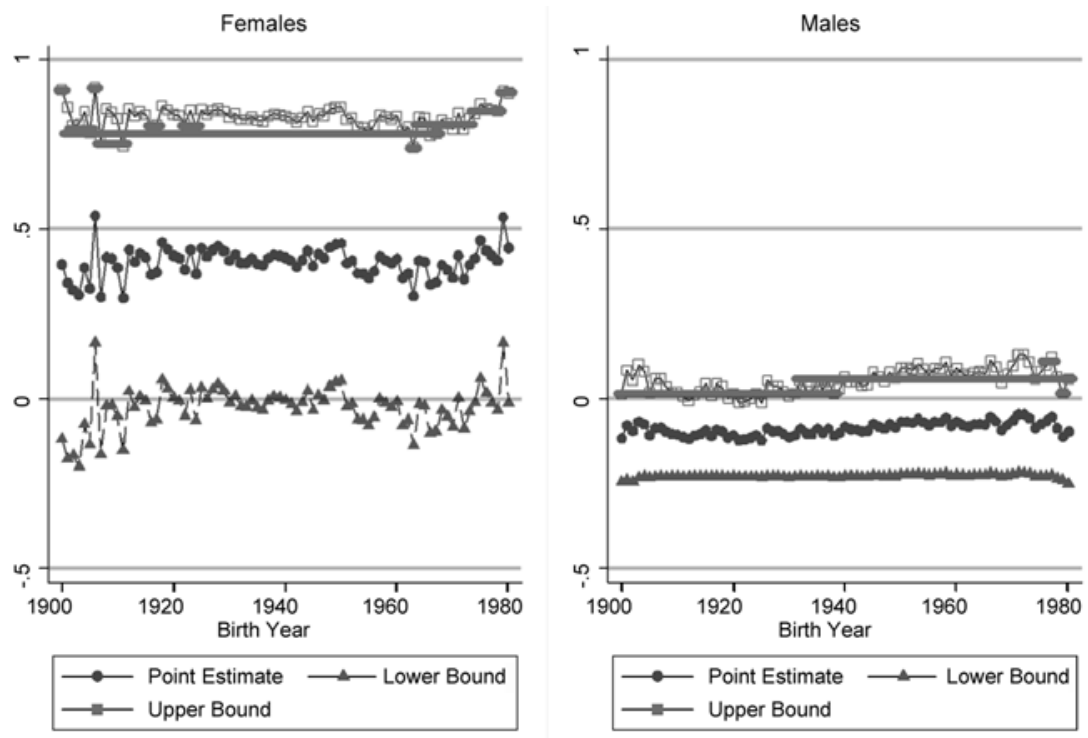

Source: Own estimates based on EUS. 
Most of the coefficients are not significant and we observe big variances in the estimates, making all the parameters statistically the same.

We include in the estimation also the years of schooling of each individual. The parameters found are negative and significant for females $(-0.028)$ and males $(-0.012)$.

Several variations of the cohort estimation were performed, such as, excluding education or using dummy variables for each year of schooling. The results are very similar for all the exercises made ${ }^{8}$.

\section{DECOMPOSITION}

Using a method proposed by Yun (2004), we can decompose differences in first moments into two components: differences in characteristics and differences in coefficients.

We separate changes in self-employment rates in these two components by estimating the probability that any individual chooses self-employment over being a blue collar or a white collar worker. First we group together blue and white collar workers and estimate a probit between two options, self-employment versus other workers. Then, we use a second strategy where we estimate a multinomial probit, allowing for three choices: self-employment, blue collar worker, or white collar worker.

The basis of the decomposition is that self-employment is a function of several characteristics, which we write in the following way:

$$
Y=F\left(X^{\prime} \beta\right)
$$

Where $\mathrm{F}$ is the C.D.F. of a normal distribution in the case of the probit and the C.D.F. of a two variate normal distribution in the case of the multinomial probit. Then the decomposition works as follows:

$$
\begin{aligned}
\bar{Y}_{t}-\bar{Y}_{t+1} & =\overline{F\left(X_{t}^{\prime} \beta_{t}\right)}-\overline{F\left(X_{t+1}{ }^{\prime} \beta_{t+1}\right)} \\
& =\overline{F\left(X_{t}^{\prime} \beta_{t}\right)}-\overline{F\left(X_{t+1}{ }^{\prime} \beta_{t}\right)}+\overline{F\left(X_{t+1}{ }^{\prime} \beta_{t}\right)}-\overline{F\left(X_{t+1}{ }^{\prime} \beta_{t+1}\right)}
\end{aligned}
$$

We call $\overline{F\left(X_{t}{ }^{\prime} \beta_{t}\right)}-\overline{F\left(X_{t+1}{ }^{\prime} \beta_{t}\right)}$ change in quantities or characteristics and $\overline{F\left(X_{t+1}{ }^{\prime} \beta_{t}\right)}-\overline{F\left(X_{t+1}{ }^{\prime} \beta_{t+1}\right)} \quad$ change in coefficients.

The characteristics that we include in the estimation are: Years of schooling, age and age squared, number of children less than 6 years old, number of children between 6 and 18 years old, a dummy for head of the household, and family income (excluding own income).

Changes in coefficients to some extent measure structural changes in the economy or in labor market institutions, such as, labor legislation, minimum

8 The results are available upon request to the authors. 
wage, liberalization, or technological change. We will draw some indirect relationships between change in coefficients and these structural changes when we analyze the decompositions by decades and relate the decomposition results to the reforms described in section two.

Changes in characteristics are mostly related to human capital and demographic changes and reflect long trends in the labor market, such as an aging process in the labor force for the last 20 years and the increase in education for workers over the whole period.

\subsection{Results for Chile}

First we decompose the change in self-employment for females and males during the whole period. In order to do this, we decompose the changes in selfemployment for each pair of consecutive years and then we added up the quantity and coefficient components ${ }^{9}$. The results are presented in Table $1^{10}$ :

TABLE 1

DECOMPOSITION FOR WHOLE PERIOD

\begin{tabular}{|c|c|c|c|c|c|}
\cline { 3 - 6 } \multicolumn{2}{c|}{} & \multicolumn{2}{c|}{ Probit } & \multicolumn{2}{c|}{ Multi Probit } \\
\hline $1965-2006$ & Total Change & Quantities & Coefficients & Quantities & Coefficients \\
\hline Females & 6.4 & 14.2 & -7.9 & 14.6 & -8.0 \\
Males & -1.2 & 2.4 & -3.6 & 5.2 & -5.6 \\
\hline
\end{tabular}

We observe that both methods give us similar insights for females, but different magnitudes for males. For females, self-employment dropped 6.4 percentage points, which, 14.2 in the case of the probit (14.6 in the case of the multinomial probit ) correspond to quantities and -7.9 for the probit ( -8 for the multinomial probit) correspond to coefficients. These results implie that, if the parameters in 2006 were the same as the ones in 1965, the drop in selfemployment would had more than doubled. In the case of males, we observe that self-employment increased by 1.2 points, however, changes in quantities reveal that self-employment should had decreased if the parameter would had not changed (2.4 points using the probit estimates and 5.2 points using the multinomial probit estimates).

Both results show that underlying changes in the economy prevent selfemployment from decreasing even further in the case of females and from decreasing in the case of males during the last 40 years. We argue below that

9 The results for the year decompositions are presented in the Appendix.

10 The decomposition is not exact, since the econometric methods are not able to perfectly predict the percentage of self-employment, there is a residual that just fit of the model to the data. 
economic activity seems more important than labor regulations to explain changes in parameters ${ }^{11}$.

The next step was to divide the whole period in two parts, for each gender. We chose the periods that present important turning points in self-employment. In the case of females, the first period corresponds from 1965 to 1983 , showing a big decrease in self-employment and the second from 1983 to 2006 when there is an increment.

TABLE 2

TWO PERIODS FEMALES

\begin{tabular}{|c|c|c|c|c|c|}
\cline { 3 - 6 } \multicolumn{1}{c|}{} & \multicolumn{2}{c|}{ Probit } & \multicolumn{2}{c|}{ Multi Probit } \\
\cline { 2 - 6 } \multicolumn{1}{c|}{} & Actual Change & Quantities & Coefficients & Quantities & Coefficients \\
\hline $1965-83$ & 9.9 & 10.5 & -0.6 & 10.4 & -1.3 \\
$1983-06$ & -3.5 & 3.7 & -7.3 & 4.2 & -6.7 \\
\hline
\end{tabular}

The decomposition results are very similar when we compare the probit and the multinomial probit. For the first period, female characteristics contributed to the decrease in self-employment and coefficients counterbalanced that trend. In the case of the second period, the rise in self-employment was mostly driven by coefficients and was counterbalanced by females characteristics.

In the case of males, the first period corresponds from 1965 to 1988 when self-employment increased by 5.2 percentage points and then, from 1988 to 2006 when self-employment dropped by almost 4 percentage points.

TABLE 3

TWO PERIODS MALES

\begin{tabular}{|c|c|c|c|c|c|}
\cline { 3 - 6 } \multicolumn{1}{c|}{} & \multicolumn{2}{c|}{ Probit } & \multicolumn{2}{c|}{ Multi Probit } \\
\cline { 2 - 6 } \multicolumn{1}{c|}{} & Actual Change & Quantities & Coefficients & Quantities & Coefficients \\
\hline $1965-88$ & -5.2 & 1.5 & -6.7 & 2.0 & -6.2 \\
$1988-06$ & 3.9 & 0.9 & 3.1 & 3.3 & -0.5 \\
\hline
\end{tabular}

The results indicate that the increase in self-employment was driven by changes in coefficients which was compensated by the change in quantities. For the second period we find that the probit and the multinomial probit suggest different patterns for the drop in self-employment. The probit results give more weight to changes in coefficients than to the change in quantities and

11 Also during this, period females labor participation increased in almost 15 percentage points. We are not considering that decision in our model, as it could also depend on growth and labor regulations. 
the multinomial probit is vice-versa. However, in both cases, coefficients and quantities approach in the same direction.

In Table 4 we present changes in self-employment in ten-year periods ${ }^{12}$.

TABLE 4

FEMALES BY DECADES

\begin{tabular}{|c|c|c|c|c|c|}
\cline { 2 - 6 } \multicolumn{1}{c|}{} & \multicolumn{2}{c|}{ Probit } & \multicolumn{2}{c|}{ Multi Probit } \\
\cline { 2 - 6 } \multicolumn{1}{c|}{} & Actual Change & Quantities & Coefficients & Quantities & Coefficients \\
\hline $1965-1976$ & 0.4 & 3.6 & -3.2 & 4.2 & -3.0 \\
$1976-1986$ & 9.3 & 7.0 & 2.3 & 7.0 & 0.8 \\
$1986-1996$ & 3.0 & 2.1 & 0.7 & 2.3 & 1.7 \\
$1996-2006$ & -6.3 & 1.5 & -7.8 & 1.1 & -7.4 \\
\hline
\end{tabular}

We will analyze the decomposition results together with the timing of the reforms that were described in section 2 of this report. During the first decade, 1965 to 1976 , the economy went from a very regulated labor market to a not regulated one, at the same time, there was a big recession in 1975. The decomposition results show a small drop in self-employment that was mostly the result of a change in quantities. The change in coefficients tends to increase self-employment, in this case it seems that the deregulation of the labor markets was not enough to decrease self-employment or that the economic cycle had a very strong effect and more than counterbalanced the deregulation results.

The second decade, from 1976 to 1986 , presents a similar level of deregulation of labor markets with a GDP that was recovering after the crisis in 1982 and 1983. From the decomposition we note that most of the drop in self-employment was due to changes in characteristics. The shift in coefficients had a low impact on self-employment. Also, we observe that the female participation rate slightly increased during this period, which implies that women were moving to salaried jobs, and that was a consequence of better human capital and not of a better economic environment.

From 1986 to 1996, economic growth was very strong and the regulation of labor markets increased. During these years self-employment decreased, mostly due to change in quantities, however the change in coefficients went in the same direction. This is indirect evidence that more regulation, joint with economic growth, does not necessarily lead to higher self-employment. This result also contradicts some of the findings of Montenegro and Pagés, specifically, that labor market regulations increased female self-employment. It is important to remember that we are using an indirect analysis, and that Montenegro and Pagés include labor market regulation variables directly in their analysis.

The last decade, from 1996 to 2006, presents a change from high economic growth to medium economic growth under similar labor market regulations. For this period self-employment increased considerably. The change in quantities

12 The data consist of 42 years, but we are studying changes, so we have 41 comparisons. Then the first period has 11 years, and the other 3 have 10 years. 
should have reduced self-employment, but the change in coefficients more than compensated for that effect and self-employment increased. As in the cohort analysis, this is evidence that economic activity affects self-employment for females.

TABLE 5

MALES BY DECADES

\begin{tabular}{|c|c|c|c|c|c|}
\cline { 3 - 6 } \multicolumn{1}{c|}{} & \multicolumn{2}{c|}{ Probit } & \multicolumn{2}{c|}{ Multi Probit } \\
\cline { 2 - 6 } \multicolumn{1}{c|}{} & Actual Change & Quantities & Coefficients & Quantities & Coefficients \\
\hline $1965-1976$ & -2.9 & 0.3 & -3.3 & 0.6 & -3.2 \\
$1976-1986$ & 1.6 & 1.4 & 0.2 & 1.4 & 0.2 \\
$1986-1996$ & 1.7 & 0.4 & 1.3 & 1.2 & 0.4 \\
$1996-2006$ & -1.6 & 0.3 & -1.8 & 2.0 & -3.1 \\
\hline
\end{tabular}

For males, in the first decade, self-employment rose by almost 3 percentage points, the decomposition results are similar for both estimation methods. The increment was promoted by changes in coefficients, the same as in the case for females, which reinforces the idea that the deregularization of the labor market was not enough to counterbalance the economic crisis of the mid seventies.

In the second decade, self-employment dropped by 1.6 percentage points, mostly because of changes in quantities. We could expect a stronger impact of coefficients, since in this period Chile had a big recession, however that did not happen, for males of females. This could be due to the especial employment programs implemented during this period which preclude a higher self-employment rate.

For the third decade, there is a discrepancy between the probit and the multinomial probit. The probit measures little change in quantities and the majority of the change is due to coefficients, however, the multinomial probit finds the opposite. Even considering this discrepancy, changes in coefficients reduced self-employment. This could be related to the high economic growth for this decade that more than compensated for the increment in labor regulation.

For the last decade, where self-employment increased, both methods agree that changes in coefficients increased self-employment, but quantities decreased. A similar results was found for women, indicating that low economic activity affects the productivity of human capital and results in greater self-employment.

The results indicate that changes in quantities always decrease self-employment, but those are long term trends as it is possible to find for some years negative variations in quantities. Changes in coefficients can go in either direction and can be large enough to increase self-employment, but they are rarely responsible for decreased self- employment.

We can argue that these findings provide indirect evidence that going from high regulation in labor markets, to no regulation at all, as in the example of the 1965 to 1976 decade, does not guarantee lower self-employment when economic activity is low at the same time. We also find that, if labor regulation increases to medium levels and comes jointly with high economic growth as 
in the 1986 to 1996 decade, self-employment tends to decrease. These results hold for females and males.

Following with more decomposition results, Yun develops a method to obtain the contribution that each characteristic and coefficient has on total quantity and coefficient changes. The decomposition is an approximation using a Taylor expansion. That seems to be inappropriate or insufficient for some years. For instance, from 1980 to 1981, changes in the education coefficients should had led to an increase by almost 11 percentage points in self-employment. In general, for males the decomposition results are less extreme. Given those results, we will focus on interpreting the results for the effects for the whole period and by decades.

Table 6 shows the decompositions for females:

TABLE 6

FEMALES BY CHARACTERISTIC

\begin{tabular}{|l|rr|rr|}
\cline { 2 - 5 } \multicolumn{1}{c|}{} & \multicolumn{2}{c|}{ Quantities } & \multicolumn{2}{c|}{ Coefficients } \\
\cline { 2 - 5 } \multicolumn{1}{c|}{} & Probit & Multi Probit & Probit & Multi Probit \\
\hline Education & 12.5 & 12.3 & 13.8 & 10.2 \\
Age & -39.0 & 2.3 & -41.2 & -3.8 \\
Age Squared & 36.1 & 5.9 & 7.0 & 7.7 \\
Children Less Than 6 & 1.1 & 1.7 & -6.6 & -13.6 \\
Children between 6 and 18 & -4.9 & 1.6 & -3.4 & 4.1 \\
Head of Household & 0.3 & -0.1 & -3.4 & -3.0 \\
Income & 8.2 & -9.1 & -4.9 & -9.6 \\
Total & 14.2 & 14.6 & -7.9 & -8.0 \\
\hline
\end{tabular}

Education plays an important role on self-employment shifts and they alone decreased self-employment by a minimum of 12 percentage points. Both methods also agree that changes in number of children in the household who are younger than 6 years decrease self-employment, however, the results differ by estimation method for the rest of the variables.

The results on coefficients exhibit that the education coefficient helped to decrease self-employment, which could be interpreted as an increment in the return to education, making salaried job more attractive than self-employment.

Also the strength of effect of the coefficient on children younger than 6 years old could be an indication that child care is more difficult to acquire in recent years. The methods differ in the effects of the coefficient for children between 6 and 18 years old. In the case of the multinomial probit they decrease self-employment, but the probit finds the opposite. Both methods agree that changes in income and head of the household parameters increase self-employment, showing that women in more vulnerable households have more problems finding salaried jobs. 
TABLE 7

MALES BY CHARACTERISTIC

\begin{tabular}{|l|rr|rr|}
\cline { 2 - 5 } \multicolumn{1}{c|}{} & \multicolumn{2}{c|}{ Quantities } & \multicolumn{2}{c|}{ Coefficients } \\
\cline { 2 - 5 } \multicolumn{1}{c|}{} & Probit & Multi Probit & Probit & Multi Probit \\
\hline \multirow{2}{*}{ Education } & 9.0 & 2.0 & 0.5 & -13.1 \\
Age & -22.2 & 2.3 & 17.7 & 56.1 \\
Age Squared & 6.1 & 1.5 & -19.9 & -49.6 \\
Children Less Than 6 & -0.7 & -1.5 & -0.2 & 1.1 \\
Children between 6 and 18 & 1.6 & -0.1 & -2.0 & -2.5 \\
Head of Household & 9.3 & 1.8 & 2.5 & 4.9 \\
Income & -0.6 & -0.9 & -2.3 & -2.5 \\
Total & 2.4 & 5.2 & -3.6 & -5.6 \\
\hline
\end{tabular}

The decomposition for males also presents important differences when the probit and the multinomial probit are compared. For instance, changes by age and age squared increase self-employment by 16 percentage points in the case of the probit and decrease it by 3.8 points when using the multinomial probit. However, the methods coincide that shifts in education decrease self-employment, with a greater effect found in the probit decomposition.

The outcomes of coefficients also differ by estimation procedure. The returns to education effect found in women is only present for males when we use the multinomial probit decomposition. As in the case of women, both methods coincide that changes in the income parameter increase self-employment for men. This finding could measure some dependence in the occupational decision as there is increasing dependence on the income of the rest of the members of the household. In the same vein, we observe that for women being head of the household increases its effect on being self-employed. For men the effects are opposite.

Table 8 presents the results for each characteristic by decade for females. We choose to present the results for the probit estimates because they are more stable during the whole period. Changes in education decreased self-employment in the first three decades but in the last decade changes in education increased self-employment. Age increased self-employment in the first three decades, but then decreased it. The number of children had an smaller effect on self-employment, except in the last decade, where the number of children between 6 and 18 years old increased self-employment by 5.3 percentage points. For the last two decades, the income of the household had a large effect on self-employment. However, the changes in education and age are the most important contributors to changes in self-employment, only income in the third decade and children between 6 and 18 in the last decade have similar effect on self-employment. 
TABLE 8

FEMALES BY DECADES

Probit, Quantities

\begin{tabular}{|l|cccc|}
\cline { 2 - 5 } \multicolumn{1}{c|}{} & $1965-1976$ & $1976-1986$ & $1986-1996$ & $1996-2006$ \\
\hline Education & 3.9 & 5.8 & 3.3 & -0.5 \\
Age & -4.3 & -0.9 & -10.3 & -23.6 \\
Age Squared & 3.4 & 0.8 & 4.7 & 27.1 \\
Children Less Than 6 & 0.3 & 0.4 & 0.0 & 0.3 \\
Children between 6 and 18 & -0.4 & 0.5 & 0.2 & -5.3 \\
Head of Household & 0.0 & 0.1 & 0.0 & 0.2 \\
Income & 0.6 & 0.2 & 4.3 & 3.2 \\
Total & 3.6 & 7.0 & 2.1 & 1.5 \\
\hline
\end{tabular}

The changes in coefficients by decade for females are presented in Table 9. Changes in the education coefficient increased self-employment in the second decade, but decreased it in the other decades. The age coefficients had the opposite effect on self-employment, decreasing it in the second decade, but increasing it in the other decades. In terms of magnitude, changes in age and education coefficients are the most important ones and the effect of the other coefficients was very low in the last decade.

In the first decade, female self-employment decreased by .4 percentage points, but the changes in characteristics and coefficients were relatively large, especially the age and education coefficients. In the second decade, there is a big drop, of 9.4 percentage points for self-employment. Again, changes in education are important and in education and age coefficients. However they have different signs. In the third decade, self-employment decreased again by 3 percentage points, changes in income, education, and the education coefficient push self-employment to low levels, but changes in age and age coefficients increased self-employment. Finally, in the last decade, when self-employment increased by 6.3 percentage points, the change in the age coefficient accounted for most of the total change.

TABLE 9

FEMALES BY DECADES

Probit, Coefficients

\begin{tabular}{|l|cccc|}
\cline { 2 - 5 } \multicolumn{1}{c|}{} & $1965-1976$ & $1976-1986$ & $1986-1996$ & $1996-2006$ \\
\hline Education & 10.2 & -7.5 & 9.0 & 2.1 \\
Age & -16.5 & 12.2 & -16.4 & -20.5 \\
Age Squared & 6.4 & 0.4 & 9.1 & 9.9 \\
Children Less Than 6 & 2.7 & 1.2 & 3.3 & -0.1 \\
Children between 6 and 18 & -1.4 & -2.2 & -3.3 & 0.3 \\
Head of Household & -2.1 & -0.7 & -0.9 & 0.3 \\
Income & -2.4 & -1.0 & -0.2 & 0.2 \\
Total & -3.2 & 2.3 & 0.7 & -7.8 \\
\hline
\end{tabular}


For males, the changes in quantities by decade are presented in Table 10. We observe that, compared to females, the magnitude of the changes are smaller, except for the last decade. Changes in education, age, and income are the most important ones. For all decades, changes in education decreased self-employment. Age had a very negative effect in the last decade, which was counterbalance by changes in the education and head of the household variables.

\begin{tabular}{|c|c|c|c|c|}
\hline & $\begin{array}{r}\text { TABL } \\
\text { MALES BY I } \\
\text { Probit, Qu }\end{array}$ & $\begin{array}{l}10 \\
\text { ECADES } \\
\text { tities }\end{array}$ & & \\
\hline & $1965-1976$ & 1976-1986 & 1986-1996 & 1996-2006 \\
\hline Education & 0.5 & 1.9 & 0.5 & 6.1 \\
\hline Age & 1.1 & 0.4 & 2.0 & -25.7 \\
\hline Age Squared & -1.5 & -0.2 & -1.5 & 9.2 \\
\hline Children Less Than 6 & -0.2 & -0.1 & -0.3 & -0.2 \\
\hline Children between 6 and 18 & 0.1 & -0.2 & 0.0 & 1.7 \\
\hline Head of Household & -0.1 & 0.0 & 0.0 & 9.4 \\
\hline Income & 0.5 & -0.4 & -0.5 & -0.2 \\
\hline Total & 0.3 & 1.4 & 0.4 & 0.4 \\
\hline
\end{tabular}

In Table 11, the results for changes in coefficients for males are shown. As in the case of females, changes in the education and age coefficients account for most of the total change. Changes in the age coefficients mimic the evolution of total self-employment, increasing in the first and last decade, and decreasing in the other two.

For the first decade when self-employment increased by 2.9 percentage points, the changes in education and age coefficients explain most of the total change. In the second decade, male self-employment decreased by 1.6 percentage points based on a combination of changes in education and the education and age coefficients. Self-employment decreased 1.7 percentage points in the third decade, mostly affected by the change in the education parameter. In the fourth decade, self-employment increased by 1.6 percentage points, but in this decade, several factors affected the total change including changes in head of the households and larger changes in education and age.

TABLE 11

MALES BY DECADES

Probit, Coefficients

\begin{tabular}{|l|rccc|}
\cline { 2 - 5 } \multicolumn{1}{c|}{} & $1965-1976$ & $1976-1986$ & $1986-1996$ & $1996-2006$ \\
\hline Education & -1.2 & -3.4 & 3.0 & 2.2 \\
Age & -3.1 & 20.1 & 4.9 & -4.1 \\
Age Squared & 1.8 & -14.6 & -4.8 & -2.4 \\
Children Less Than 6 & -0.2 & -0.7 & 0.3 & 0.4 \\
Children between 6 and 18 & -0.1 & -0.1 & -1.6 & -0.2 \\
Head of Household & -0.5 & -0.1 & 0.2 & 2.9 \\
Income & 0.2 & -1.1 & -0.7 & -0.6 \\
Total & -3.3 & 0.2 & 1.3 & -1.8 \\
\hline
\end{tabular}


In summary, the decomposition by characteristics shows important differences by method used. However, they agree that education has a strong effect on decreasing self-employment. Also, for women we find evidence that the return to education is decreasing self-employment, but the evidence is mixed for men.

The coefficient on income indicates, for females and males, that the occupational decision is being increasingly affected by the income of rest of the household members.

When we analyze by decade, we find that the components with the biggest changes are age, education, and the coefficients in age and education. For females, changes in age and age coefficients tend to increase self-employment, and only changes in education and the education coefficient prevent a higher self-employment rate. For males, changes in education tend to decrease selfemployment. For the last decade, changes in age and the age coefficient are increasing self-employment.

Changes in education and age are easy to predict. In the last decades the Chilean educational system has expanded enormously, first in secondary education, and lately in terciary or college education. Also, an important aging process is observed. However, changes in parameters are not correlated with other variables in a clear way and, thus predicting them is impossible. This fact makes it difficult to gain a broader understanding of the general trends in self-employment, but open opportunities to new research focusing on structural changes that affect the prices of each attribute in the decision equations.

\section{Conclusions}

In this paper we analyze the evolution of self-employment in Chile during the last 40 years. During this period several important changes are observed in the economic structure including several episodes of recession and growth.

In the sample, we find that self-employed workers receive a lower wage than white collar workers, but higher than blue collar workers, and that the self-employment category presents relatively high income dispersion. Most self-employed workers do not have a college degree. This implies that this occupational group does not include skilled individuals who become self-employed because of the advantages in flexibility that this occupation would give.

During the whole period, we observe different trends for females and males. In the case of females, self- employment decreased, especially from 1965 to 1983, and then increased slightly after that. For males, it increased in a small proportion from 1965 to 1988, and decreased afterwards. Generally self-employment was not affected by recessions, perhaps due to the result of government effort to reduce unemployment via emergency programs. However, for women, we find that during the 1985 to 1996 period, which exhibits high economic growth, self- employment decreased.

We decompose changes in self-employment into two parts: changes in characteristics and changes in coefficients. For most of the decompositions, we found that changes in characteristics tend to decrease self-employment, 
however this effect is counterbalanced by changes in coefficients. The change in parameters presents evidence that structural changes in the Chilean economy have led to increments in self-employment. There is also indirect evidence that the labor reforms of the early nineties did not increase self-employment or that their effect was greatly counterbalanced by economic growth.

\section{REFERENCES}

Amuedo-Dorantes, C (2004). "Determinants and Poverty Implications of Informal Sector Work in Chile", in Economic Development and Cultural Change. The University of Chicago Press.

Blanchard, O. and P. Diamond (1990). "The Cyclical Behavior of the Gross Flows of US Workers". Brookings Papers on Economics Activity 2: 85-142.

Bosworth B.; Dornbush, R. and R. Labán (eds.) (1994). The Chilean Economy. Policy Lessons and Challenges. Washington DC. Brookings Institution.

Caballero, R., E. Engel and A. Micco (2005). Microeconomic Flexibility in Latin America. Labor Market and Institutions. Banco Central de Chile. (J. Restrepo and A. Tokman, editors).

Charmes, J. (1998). "Informal Sector, Poverty and Gender: A Review of Empirical Evidence". Background Paper for World Development Report 2001. World Bank, Washington, D.C.

Djankov, S., I. Lieberman, J. Mukherjee, and T. Nenova (2002). "Going Informal: Benefits and Costs" World Bank, Washington, D.C.

De Gregorio, J. (1999). "Exchange Rate Policy in Chile Since 1960: Political Economy and The Choice of Regime". Centro de Economía Aplicada, Universidad de Chile. Mimeo.

Edwards, S. and A. Cox-Edwards (1987). Monetarism and Liberalization: The Chilean Experience. Cambridge, Mass. Balinguer.

Edwards, S. and A. Cox-Edwards (2000). "Policy Issues and Lessons from Chile", NBER Working Paper 7646.

Edwards, S. and A. Cox-Edwards (2002). "Social Security Privatization Reform and Labor Markets: The Case of Chile", Economic Development and Cultural Change 465-489.

Edwards, S. and D. Lederman (1998). "The Political Economy of Unilateral Trade Liberalization: The Case of Chile". NBER Working Paper $\mathrm{N}^{\circ} 6510$.

Feres, M. E. (1997). "Sindicalismo y Negociación Colectiva", in La Negociación Colectiva en Chile, Santiago: Editorial Gestión.

Gill, I., C. Montenegro and D. Domeland (eds.) (2002). Crafting Labor Policy. Techniques and Lessons from Latin America. The World Bank. Chapter 6 and 7.

Heckman, J. and C. Pagés (2000). "The Cost of Job Security Regulation: Evidence from Latin American Labor Markets". Economía 1 (1): 147-51.

International Labour Organization (2002). "Decent Work and the Informal Economy", Report VI, International Labour Conference, $90^{\text {th }}$ Session, Geneva.

Kugler, A. (2000). "The incidence of Job Security Regulation on Labor Market Flexibility and Compliance in Colombia: Evidence from the 1990 Reform". Research Network Working Paper R-393. Washington DC. IADB. 
Mizala, A. and P. Romaguera (2001). "La Lesgislación Laboral y el Mercado del Trabajo en Chile: 1975-2000”, Working Paper, № 114. CEA.

Montenegro, C. and Pagés, C. (2003). "Who Benefits from Labor Market Regulations?: Chile 1960-1998", Inter-American Development Bank. Banco Interamericano de Desarrollo (BID) Research Department, Working Paper 494.

Palmade, V. and A. Anayiotos (2005). "Rising Informality", The World Bank Group, Private Sector Development, Note Number 298.

Pagés, C. and C. Montenegro (1999). "Job Security and the age Composition of Employment: Evidence from Chile”. Working Paper 398. Washington DC. IADB.

Restrepo, J. and A. Tokman (2005). Labor Markets and Institutions, Banco Central de Chile.

Saavedra, J. and M. Torero (2000). "Labor Market Reforms and their Impact Over Formal Labor Demand and Job Market Turnover: The case of Perú". Research Network Working Paper R-394. Washington DC. IADB.

Yun, N. (2004). "Decomposing differences in the first moment", Economics Letters 82: 275-280. 
TABLE A1

GENERAL ECONOMIC INDICATORS: CHILE 1965-2006

\begin{tabular}{|c|c|c|c|c|c|c|}
\hline Year & $\begin{array}{c}\text { GDP } \\
\text { per capita } \\
\text { growth } \\
(\text { annual \%) }\end{array}$ & $\begin{array}{c}\text { Exports } \\
\text { (annual \%) }\end{array}$ & $\begin{array}{c}\text { Inflation, } \\
\text { consumer } \\
\text { prices } \\
(\text { annual \%) }\end{array}$ & $\begin{array}{c}\text { Gran Santiago } \\
\text { Unemployment } \\
\text { (\% of total } \\
\text { labor force) }\end{array}$ & $\begin{array}{c}\text { National } \\
\text { Unemployment, } \\
\text { total } \\
\text { (\% total } \\
\text { labor force) }\end{array}$ & $\begin{array}{c}\text { Gini } \\
\text { Coefficient }\end{array}$ \\
\hline 1965 & $-1,8$ & & 28,8 & 5,1 & & 48,8 \\
\hline 1966 & 7,6 & & 23,1 & 6,1 & & 47,3 \\
\hline 1967 & 1,5 & & 18,8 & 5,9 & & 53,8 \\
\hline 1968 & 1,6 & & 26,3 & 6,6 & & 51,4 \\
\hline 1969 & 1,5 & & 30,4 & 7,5 & & 51,2 \\
\hline 1970 & 0,2 & & 32,5 & 7,3 & & 50,3 \\
\hline 1971 & 7,1 & & 20,0 & 5,3 & & 48,3 \\
\hline 1972 & $-2,5$ & & 74,8 & 3,7 & & 47,1 \\
\hline 1973 & $-6,5$ & & 361,5 & 3,0 & & 46,7 \\
\hline 1974 & 0,8 & & 504,7 & 10,7 & & 45,6 \\
\hline 1975 & $-12,8$ & & 374,7 & 16,4 & & 50,4 \\
\hline 1976 & 1,8 & & 211,8 & 18,4 & & 53,5 \\
\hline 1977 & 7,1 & & 91,9 & 13,3 & & 53,8 \\
\hline 1978 & 5,9 & & 40,1 & 13,0 & & 53,0 \\
\hline 1979 & 7,1 & & 33,4 & 12,7 & & 51,7 \\
\hline 1980 & 6,5 & & 35,1 & 11,9 & & 53,2 \\
\hline 1981 & 3,2 & & 19,7 & 9,2 & & 56,8 \\
\hline 1982 & $-11,7$ & & 9,9 & 23,6 & & 58,4 \\
\hline 1983 & $-5,3$ & & 27,3 & 23,0 & & 56,2 \\
\hline 1984 & 6,3 & & 19,9 & 18,7 & & 59,8 \\
\hline 1985 & 5,4 & & 29,5 & 16,4 & & 57,7 \\
\hline 1986 & 3,9 & & 20,6 & 15,6 & 12,1 & 56,9 \\
\hline 1987 & 3,6 & 6,7 & 19,9 & 13,7 & 10,9 & 61,0 \\
\hline 1988 & 5,8 & 11,6 & 14,7 & 11,3 & 9,7 & 58,3 \\
\hline 1989 & 8,8 & 16,1 & 17,0 & 9,4 & 7,9 & 56,1 \\
\hline 1990 & 1,8 & 8,6 & 26,0 & 9,9 & 7,7 & 58,7 \\
\hline 1991 & 5,4 & 12,4 & 21,8 & 8,4 & 8,1 & 55,9 \\
\hline 1992 & 11,1 & 13,9 & 15,4 & 6,0 & 6,7 & 51,5 \\
\hline 1993 & 5,7 & 3,5 & 12,7 & 6,5 & 6,5 & 52,0 \\
\hline 1994 & 4,2 & 11,6 & 11,4 & 6,3 & 7,8 & 51,8 \\
\hline 1995 & 6,9 & 11,0 & 8,2 & 6,2 & 7,3 & 53,2 \\
\hline 1996 & 6,9 & 11,8 & 7,4 & 7,3 & 6,3 & 53,7 \\
\hline 1997 & 5,2 & 11,2 & 6,1 & 6,8 & 6,1 & 54,4 \\
\hline 1998 & 1,9 & 5,2 & 5,1 & 7,0 & 6,4 & 55,6 \\
\hline 1999 & $-2,1$ & 7,3 & 3,3 & 15,6 & 10,2 & 58,0 \\
\hline 2000 & 3,1 & 5,1 & 3,8 & 14,5 & 9,8 & 56,9 \\
\hline 2001 & 2,2 & 7,2 & 3,6 & 15,2 & 9,9 & 52,9 \\
\hline 2002 & 1,1 & 1,6 & 2,5 & 13,7 & 9,8 & 54,2 \\
\hline 2003 & 2,8 & 6,5 & 2,8 & 13,5 & 9,5 & 52,5 \\
\hline 2004 & 5,0 & 11,8 & 1,1 & 11,7 & 10,0 & 52,8 \\
\hline 2005 & 5,2 & 6,1 & 3,1 & 11,6 & 9,2 & 57,5 \\
\hline 2006 & & & & 11,2 & & 52,2 \\
\hline
\end{tabular}

Sources: Montenegro and Pagés (2003), World Bank World Development Indicators Data Base, INE, Central Bank and Own Calculations Using Employment Survey 


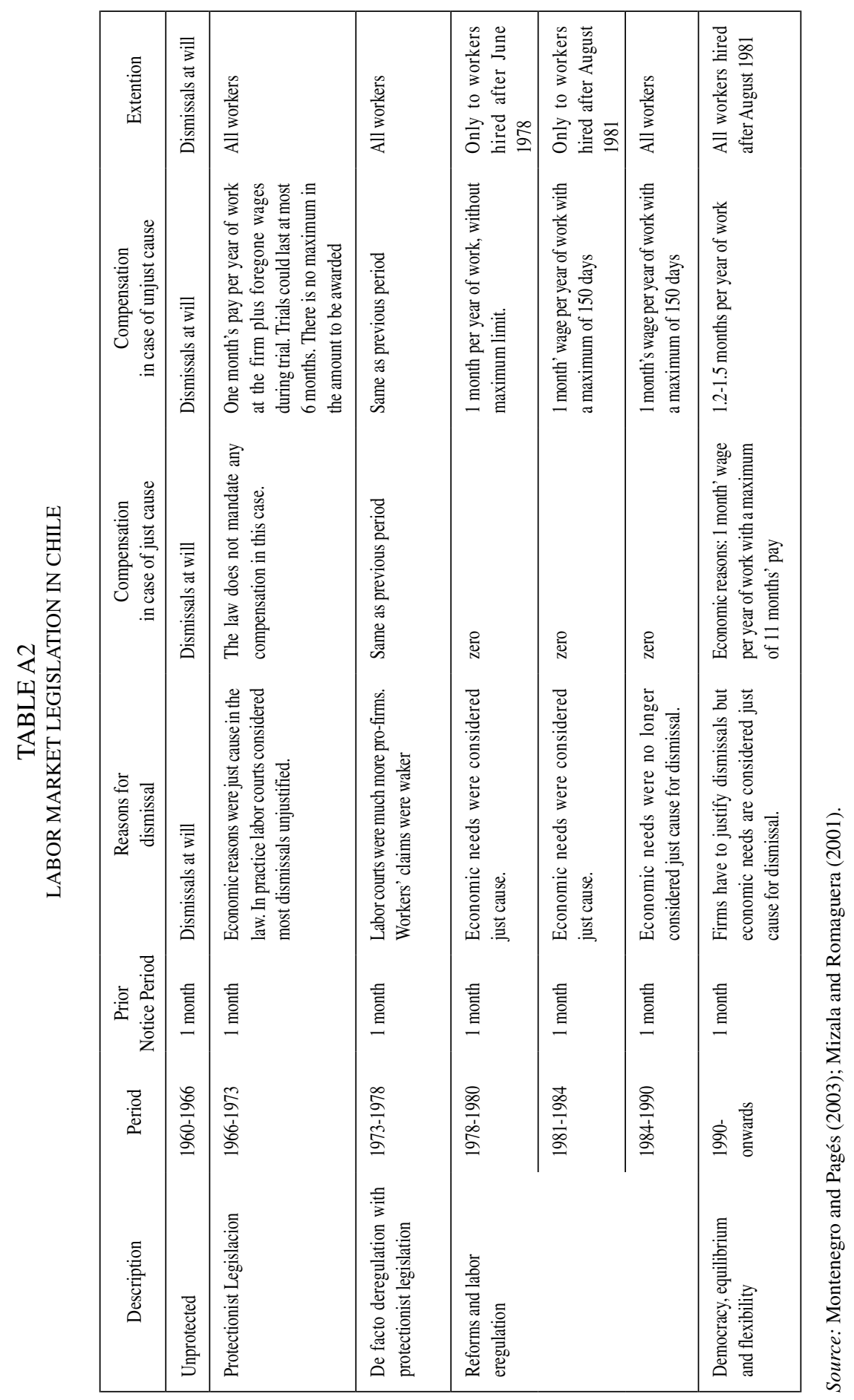


TABLE A3

FEMALES PROBIT DECOMPOSITION

\begin{tabular}{|c|c|c|c|c|}
\hline & Quantities & Coefficients & $\mathrm{Q}+\mathrm{P}$ & Actual Change \\
\hline $1965-66$ & -0.27 & -3.66 & -3.93 & -3.90 \\
\hline $1966-67$ & 0.11 & 2.87 & 2.98 & 2.91 \\
\hline $1967-68$ & 0.48 & -3.15 & -2.67 & -2.61 \\
\hline $1968-69$ & -1.62 & 0.49 & -1.14 & -1.19 \\
\hline $1969-70$ & 1.80 & 4.53 & 6.34 & 6.42 \\
\hline $1970-71$ & 1.66 & -2.37 & -0.71 & -0.86 \\
\hline $1971-72$ & -0.60 & 1.30 & 0.70 & 0.77 \\
\hline $1972-73$ & 0.94 & -1.81 & -0.87 & -0.91 \\
\hline $1973-74$ & -2.67 & -5.09 & -7.77 & -7.70 \\
\hline $1974-75$ & 2.96 & 4.68 & 7.64 & 7.52 \\
\hline $1975-76$ & 0.79 & -0.99 & -0.20 & -0.08 \\
\hline $1976-77$ & 2.79 & 2.06 & 4.85 & 4.97 \\
\hline $1977-78$ & -0.21 & -0.50 & -0.71 & -0.85 \\
\hline $1978-79$ & 1.60 & -3.55 & -1.95 & -1.99 \\
\hline $1979-80$ & 0.93 & 0.94 & 1.87 & 1.93 \\
\hline $1980-81$ & -0.39 & -1.57 & -1.96 & -1.95 \\
\hline $1981-82$ & 1.68 & 2.27 & 3.95 & 3.75 \\
\hline $1982-83$ & 0.54 & 2.92 & 3.46 & 3.63 \\
\hline $1983-84$ & 0.87 & -2.02 & -1.15 & -1.16 \\
\hline $1984-85$ & -0.19 & 1.66 & 1.47 & 1.44 \\
\hline $1985-86$ & -0.60 & 0.13 & -0.48 & -0.47 \\
\hline $1986-87$ & 0.54 & -0.75 & -0.21 & -0.18 \\
\hline $1987-88$ & -0.96 & -1.97 & -2.93 & -2.92 \\
\hline $1988-89$ & 2.17 & 0.25 & 2.42 & 2.36 \\
\hline $1989-90$ & 0.16 & 0.85 & 1.01 & 1.15 \\
\hline $1990-91$ & -0.26 & -2.51 & -2.77 & -2.78 \\
\hline $1991-92$ & 0.23 & 2.12 & 2.36 & 2.29 \\
\hline $1992-93$ & -0.43 & 2.64 & 2.21 & 2.28 \\
\hline 1993-94 & 0.96 & -0.42 & 0.54 & 0.53 \\
\hline $1994-95$ & -0.85 & 0.67 & -0.18 & -0.18 \\
\hline $1995-96$ & 0.57 & -0.14 & 0.43 & 0.43 \\
\hline $1996-97$ & 0.14 & -0.38 & -0.25 & -0.28 \\
\hline $1997-98$ & 1.76 & -3.71 & -1.95 & -1.99 \\
\hline $1998-99$ & -1.93 & -0.77 & -2.70 & -2.65 \\
\hline 1999-00 & 0.97 & 2.74 & 3.70 & 3.73 \\
\hline $2000-01$ & -0.36 & -3.22 & -3.58 & -3.56 \\
\hline 2001-02 & -0.40 & 0.41 & 0.01 & -0.10 \\
\hline $2002-03$ & 0.84 & -0.01 & 0.83 & 0.89 \\
\hline 2003-04 & 0.03 & 1.25 & 1.29 & 1.24 \\
\hline 2004-05 & 0.10 & 0.04 & 0.15 & 0.18 \\
\hline 2005-06 & 0.34 & -4.13 & -3.79 & -3.75 \\
\hline Total & 14.24 & -7.92 & 6.32 & 6.37 \\
\hline
\end{tabular}


TABLE A4

MALES PROBIT DECOMPOSITION

\begin{tabular}{|c|c|c|c|c|}
\hline & Quantities & Coefficients & $\mathrm{Q}+\mathrm{P}$ & Actual Change \\
\hline $1965-66$ & -0.09 & 1.66 & 1.57 & 1.58 \\
\hline $1966-67$ & 0.38 & 0.21 & 0.59 & 0.59 \\
\hline $1967-68$ & 0.24 & -1.74 & -1.51 & -1.51 \\
\hline $1968-69$ & -0.12 & 0.98 & 0.86 & 0.86 \\
\hline $1969-70$ & -0.11 & -1.82 & -1.93 & -1.93 \\
\hline $1970-71$ & -0.19 & 1.20 & 1.00 & 0.99 \\
\hline $1971-72$ & 0.47 & -0.81 & -0.34 & -0.33 \\
\hline $1972-73$ & -0.10 & -0.89 & -0.99 & -1.00 \\
\hline $1973-74$ & -0.65 & 0.67 & 0.02 & 0.03 \\
\hline $1974-75$ & 0.30 & -0.77 & -0.47 & -0.47 \\
\hline $1975-76$ & 0.19 & -1.93 & -1.75 & -1.74 \\
\hline $1976-77$ & 0.32 & 2.69 & 3.01 & 3.00 \\
\hline $1977-78$ & 0.33 & -1.61 & -1.27 & -1.27 \\
\hline $1978-79$ & -0.26 & -1.71 & -1.97 & -1.98 \\
\hline $1979-80$ & 0.35 & -0.42 & -0.07 & -0.07 \\
\hline $1980-81$ & 0.13 & 1.22 & 1.35 & 1.36 \\
\hline $1981-82$ & 0.12 & 0.06 & 0.18 & 0.17 \\
\hline $1982-83$ & -0.12 & -1.79 & -1.91 & -1.90 \\
\hline $1983-84$ & 0.38 & -0.20 & 0.18 & 0.17 \\
\hline $1984-85$ & -0.14 & 2.15 & 2.02 & 2.03 \\
\hline $1985-86$ & 0.30 & -0.21 & 0.09 & 0.07 \\
\hline $1986-87$ & -0.21 & -0.31 & -0.52 & -0.52 \\
\hline $1987-88$ & -0.01 & -3.29 & -3.30 & -3.31 \\
\hline $1988-89$ & 0.87 & 3.27 & 4.15 & 4.15 \\
\hline $1989-90$ & -0.10 & 0.42 & 0.33 & 0.34 \\
\hline 1990-91 & -0.46 & -0.94 & -1.39 & -1.39 \\
\hline $1991-92$ & -0.35 & 0.96 & 0.61 & 0.60 \\
\hline $1992-93$ & 0.18 & 1.61 & 1.79 & 1.80 \\
\hline 1993-94 & 0.02 & -1.04 & -1.01 & -1.02 \\
\hline 1994-95 & 0.19 & 0.54 & 0.73 & 0.72 \\
\hline $1995-96$ & 0.23 & 0.06 & 0.30 & 0.32 \\
\hline $1996-97$ & 0.14 & -0.33 & -0.19 & -0.23 \\
\hline $1997-98$ & 0.39 & -2.17 & -1.78 & -1.79 \\
\hline 1998-99 & -0.08 & -0.46 & -0.54 & -0.51 \\
\hline 1999-00 & 0.36 & 1.45 & 1.81 & 1.81 \\
\hline $2000-01$ & -0.17 & 1.18 & 1.01 & 1.03 \\
\hline 2001-02 & -0.25 & -0.59 & -0.84 & -0.86 \\
\hline $2002-03$ & 0.25 & 0.82 & 1.07 & 1.07 \\
\hline 2003-04 & -0.18 & -4.11 & -4.30 & -4.30 \\
\hline 2004-05 & -0.03 & 1.67 & 1.63 & 1.64 \\
\hline 2005-06 & -0.16 & 0.72 & 0.56 & 0.57 \\
\hline Total & 2.37 & -3.60 & -1.23 & -1.23 \\
\hline
\end{tabular}


TABLE A5

FEMALES QUANTITIES, PROBIT DECOMPOSITION

\begin{tabular}{|c|c|c|c|c|c|c|c|c|}
\hline & Education & Age & $\begin{array}{c}\text { Age } \\
\text { Squared }\end{array}$ & $\begin{array}{c}\text { Children } \\
\text { less } \\
\text { than } 6\end{array}$ & $\begin{array}{c}\text { Children } \\
6 \text { to } 18\end{array}$ & $\begin{array}{l}\text { Head } \\
\text { of } \mathrm{HH}\end{array}$ & Income & Total \\
\hline $1965-66$ & 0.3 & -2.2 & 1.4 & 0.1 & 0.1 & 0.3 & -0.2 & -0.3 \\
\hline $1966-67$ & 0.1 & 0.2 & -0.1 & 0.0 & -0.1 & 0.0 & -0.1 & 0.1 \\
\hline $1967-68$ & 1.6 & -2.9 & 1.9 & 0.1 & -0.1 & -0.1 & 0.0 & 0.5 \\
\hline 1968-69 & -0.1 & 0.7 & -0.3 & -0.4 & -1.3 & -0.1 & -0.3 & -1.6 \\
\hline $1969-70$ & 1.1 & -0.8 & 0.4 & 0.2 & 0.7 & -0.1 & 0.3 & 1.8 \\
\hline 1970-71 & 0.9 & 0.3 & 0.0 & 0.0 & 0.0 & 0.1 & 0.5 & 1.7 \\
\hline $1971-72$ & -0.7 & 0.0 & 0.4 & 0.0 & -0.2 & -0.1 & 0.0 & -0.6 \\
\hline $1972-73$ & 0.4 & 0.1 & 0.0 & 0.0 & 0.2 & -0.1 & 0.3 & 0.9 \\
\hline 1973-74 & -2.0 & -0.2 & 0.1 & 0.2 & -0.6 & 0.1 & -0.1 & -2.7 \\
\hline 1974-75 & 1.8 & 0.0 & 0.1 & 0.1 & 0.9 & 0.1 & 0.0 & 3.0 \\
\hline $1975-76$ & 0.4 & 0.7 & -0.3 & 0.0 & 0.0 & 0.0 & 0.0 & 0.8 \\
\hline 1976-77 & 1.7 & 0.1 & 0.0 & 0.1 & 0.0 & 0.0 & 0.7 & 2.8 \\
\hline $1977-78$ & -0.2 & 0.0 & -0.3 & 0.0 & 0.0 & 0.0 & 0.2 & -0.2 \\
\hline $1978-79$ & 0.8 & 0.0 & 0.0 & 0.0 & 0.2 & 0.0 & 0.6 & 1.6 \\
\hline 1979-80 & 0.2 & 0.1 & 0.4 & 0.0 & 0.3 & 0.0 & 0.0 & 0.9 \\
\hline $1980-81$ & 0.2 & -0.3 & -0.1 & 0.0 & -0.1 & 0.0 & 0.0 & -0.4 \\
\hline $1981-82$ & 1.4 & -0.2 & 0.0 & 0.2 & 0.3 & 0.1 & 0.0 & 1.7 \\
\hline $1982-83$ & 0.7 & 2.5 & -1.2 & 0.1 & -0.1 & 0.0 & -1.4 & 0.5 \\
\hline $1983-84$ & 0.3 & 1.7 & -1.1 & 0.1 & 0.0 & 0.0 & 0.0 & 0.9 \\
\hline 1984-85 & -0.1 & -0.9 & 0.5 & 0.0 & 0.1 & 0.0 & 0.1 & -0.2 \\
\hline $1985-86$ & 0.7 & -4.0 & 2.7 & 0.1 & 0.0 & 0.0 & -0.1 & -0.6 \\
\hline 1986-87 & 0.3 & 0.1 & 0.1 & 0.0 & 0.1 & 0.0 & -0.1 & 0.5 \\
\hline 1987-88 & -0.9 & 0.0 & 0.0 & -0.1 & -0.1 & 0.0 & 0.2 & -1.0 \\
\hline 1988-89 & 2.4 & -0.1 & 0.0 & -0.1 & 0.3 & 0.0 & -0.3 & 2.2 \\
\hline $1989-90$ & 0.0 & 0.1 & 0.0 & 0.0 & 0.1 & 0.1 & 0.0 & 0.2 \\
\hline 1990-91 & -0.2 & 0.0 & 0.0 & 0.0 & 0.0 & 0.0 & 0.0 & -0.3 \\
\hline 1991-92 & -0.1 & 0.2 & 0.0 & 0.0 & 0.0 & 0.0 & 0.1 & 0.2 \\
\hline $1992-93$ & 1.4 & -10.3 & 4.1 & -0.1 & -0.3 & 0.0 & 4.9 & -0.4 \\
\hline 1993-94 & 0.9 & 0.4 & 0.0 & 0.0 & 0.3 & -0.1 & -0.4 & 1.0 \\
\hline 1994-95 & -0.6 & -0.7 & 0.5 & 0.0 & -0.1 & 0.0 & 0.0 & -0.9 \\
\hline $1995-96$ & 0.2 & 0.1 & 0.1 & 0.2 & -0.1 & 0.0 & 0.0 & 0.6 \\
\hline 1996-97 & 0.3 & -0.3 & 0.1 & 0.0 & 0.0 & 0.0 & 0.0 & 0.1 \\
\hline $1997-98$ & 1.4 & 0.2 & 0.0 & 0.0 & -0.1 & 0.0 & 0.3 & 1.8 \\
\hline 1998-99 & -0.7 & -5.5 & 4.3 & 0.0 & 0.0 & 0.1 & -0.1 & -1.9 \\
\hline 1999-00 & 0.2 & 1.4 & -0.8 & 0.0 & 0.0 & 0.0 & 0.1 & 1.0 \\
\hline 2000-01 & 0.0 & -1.7 & 1.4 & 0.0 & 0.0 & 0.0 & 0.1 & -0.4 \\
\hline 2001-02 & -0.5 & 0.0 & -0.1 & -0.1 & 0.1 & 0.0 & 0.1 & -0.4 \\
\hline $2002-03$ & 1.2 & 0.3 & -0.7 & -0.1 & 0.0 & 0.0 & 0.0 & 0.8 \\
\hline 2003-04 & -0.2 & -0.1 & 0.3 & 0.0 & 0.1 & 0.0 & 0.0 & 0.0 \\
\hline 2004-05 & -2.7 & -20.4 & 25.5 & 0.5 & -5.4 & 0.0 & 2.5 & 0.1 \\
\hline 2005-06 & 0.5 & 2.5 & -3.0 & 0.0 & 0.0 & 0.0 & 0.3 & 0.3 \\
\hline Total & 12.5 & -39.0 & 36.1 & 1.1 & -4.9 & 0.3 & 8.2 & 14.2 \\
\hline
\end{tabular}


TABLE A6

FEMALE COEFFICIENTS, PROBIT DECOMPOSITION

\begin{tabular}{|c|c|c|c|c|c|c|c|c|}
\hline & Education & Age & $\begin{array}{c}\text { Age } \\
\text { Squared }\end{array}$ & $\begin{array}{c}\text { Children } \\
\text { less } \\
\text { than } 6\end{array}$ & $\begin{array}{c}\text { Children } \\
6 \text { to } 18\end{array}$ & $\begin{array}{l}\text { Head } \\
\text { of } \mathrm{HH}\end{array}$ & Income & Total \\
\hline $1965-66$ & -0.6 & -5.6 & 2.4 & -0.2 & 0.0 & 0.4 & -0.1 & -3.7 \\
\hline 1966-67 & 0.0 & 5.4 & -2.3 & 0.1 & -0.3 & 0.0 & -0.1 & 2.9 \\
\hline $1967-68$ & 0.3 & -6.2 & 2.9 & 0.0 & 0.2 & -0.2 & -0.2 & -3.2 \\
\hline 1968-69 & 1.0 & -1.4 & 0.9 & 0.2 & 0.3 & -0.5 & -0.2 & 0.5 \\
\hline $1969-70$ & 0.0 & 7.0 & -4.1 & 0.2 & 0.4 & 0.9 & 0.3 & 4.5 \\
\hline $1970-71$ & -0.5 & -3.8 & 1.7 & 0.1 & 0.2 & 0.1 & -0.1 & -2.4 \\
\hline $1971-72$ & 0.2 & 1.6 & -0.8 & 0.0 & 0.0 & 0.1 & 0.2 & 1.3 \\
\hline $1972-73$ & 0.1 & -3.8 & 1.6 & 0.1 & 0.0 & 0.0 & 0.1 & -1.8 \\
\hline $1973-74$ & 0.5 & -10.2 & 3.6 & 0.4 & 0.3 & -0.1 & 0.3 & -5.1 \\
\hline $1974-75$ & 8.9 & 2.6 & -0.7 & 2.0 & -2.7 & -2.7 & -2.6 & 4.7 \\
\hline $1975-76$ & 0.3 & -2.1 & 1.1 & -0.2 & 0.0 & 0.0 & -0.1 & -1.0 \\
\hline $1976-77$ & 0.4 & 3.2 & -1.9 & -0.2 & 0.3 & 0.2 & 0.1 & 2.1 \\
\hline $1977-78$ & 0.1 & -1.4 & 1.0 & 0.0 & -0.1 & -0.1 & 0.0 & -0.5 \\
\hline 1978-79 & -0.9 & -8.2 & 5.3 & 0.2 & -0.2 & -0.5 & 0.8 & -3.6 \\
\hline 1979-80 & 0.5 & 0.6 & -0.3 & 0.0 & 0.1 & 0.1 & 0.0 & 0.9 \\
\hline $1980-81$ & -10.9 & 13.3 & -2.3 & 1.7 & -1.5 & -0.8 & -1.0 & -1.6 \\
\hline $1981-82$ & -1.3 & 9.5 & -4.3 & -0.5 & -0.5 & 0.2 & -0.8 & 2.3 \\
\hline $1982-83$ & 1.1 & 3.1 & -1.4 & 0.0 & -0.1 & 0.0 & 0.1 & 2.9 \\
\hline 1983-84 & -0.2 & -3.9 & 1.7 & 0.1 & 0.2 & 0.0 & 0.1 & -2.0 \\
\hline $1984-85$ & 3.8 & -4.2 & 2.8 & -0.1 & -0.4 & 0.1 & -0.3 & 1.7 \\
\hline $1985-86$ & 0.0 & 0.3 & -0.2 & 0.0 & 0.0 & 0.0 & 0.0 & 0.1 \\
\hline $1986-87$ & 9.2 & -18.2 & 10.6 & 1.9 & -2.5 & -0.7 & -1.1 & -0.8 \\
\hline $1987-88$ & 0.2 & -4.8 & 2.5 & 1.1 & -0.8 & -0.4 & 0.3 & -2.0 \\
\hline 1988-89 & 0.0 & 0.5 & -0.2 & 0.0 & 0.0 & 0.0 & 0.0 & 0.3 \\
\hline $1989-90$ & -0.4 & 2.7 & -1.4 & 0.0 & 0.0 & -0.1 & 0.0 & 0.8 \\
\hline $1990-91$ & 0.2 & -5.8 & 3.1 & 0.0 & 0.2 & 0.0 & -0.1 & -2.5 \\
\hline $1991-92$ & -0.5 & 4.4 & -1.8 & -0.1 & -0.2 & 0.0 & 0.3 & 2.1 \\
\hline $1992-93$ & 0.3 & 4.8 & -3.6 & 0.5 & 0.0 & 0.3 & 0.4 & 2.6 \\
\hline 1993-94 & 0.1 & -1.0 & 0.5 & 0.0 & 0.0 & 0.0 & -0.1 & -0.4 \\
\hline 1994-95 & -0.1 & 1.6 & -0.7 & 0.0 & 0.0 & 0.0 & 0.0 & 0.7 \\
\hline $1995-96$ & 0.0 & -0.3 & 0.2 & 0.0 & 0.0 & 0.0 & 0.0 & -0.1 \\
\hline 1996-97 & 0.0 & -0.8 & 0.4 & 0.0 & 0.0 & 0.0 & 0.0 & -0.4 \\
\hline $1997-98$ & 0.9 & -10.1 & 5.3 & 0.0 & 0.2 & 0.1 & -0.1 & -3.7 \\
\hline 1998-99 & 0.1 & -2.2 & 1.3 & 0.0 & 0.0 & 0.0 & 0.1 & -0.8 \\
\hline 1999-00 & 0.7 & 6.2 & -3.9 & -0.1 & -0.2 & 0.1 & -0.1 & 2.7 \\
\hline 2000-01 & 0.2 & -7.6 & 4.2 & 0.0 & 0.2 & -0.1 & -0.1 & -3.2 \\
\hline 2001-02 & 0.1 & 0.3 & 0.0 & 0.0 & 0.0 & 0.0 & 0.0 & 0.4 \\
\hline 2002-03 & 0.0 & 0.0 & 0.0 & 0.0 & 0.0 & 0.0 & 0.0 & 0.0 \\
\hline 2003-04 & 0.0 & 2.1 & -1.0 & 0.0 & 0.0 & 0.0 & 0.0 & 1.3 \\
\hline 2004-05 & 0.0 & 0.2 & -0.1 & 0.0 & 0.0 & 0.0 & 0.0 & 0.0 \\
\hline 2005-06 & 0.0 & -8.6 & 3.8 & -0.1 & 0.1 & 0.2 & 0.3 & -4.1 \\
\hline Total & 13.8 & -41.2 & 25.8 & 7.0 & -6.6 & -3.4 & -3.4 & -7.9 \\
\hline
\end{tabular}


TABLE A7

MALES QUANTITIES, PROBIT DECOMPOSITION

\begin{tabular}{|c|c|c|c|c|c|c|c|c|}
\hline & Education & Age & $\begin{array}{c}\text { Age } \\
\text { Squared }\end{array}$ & $\begin{array}{c}\text { Children } \\
\text { less } \\
\text { than } 6\end{array}$ & $\begin{array}{c}\text { Children } \\
6 \text { to } 18\end{array}$ & $\begin{array}{l}\text { Head } \\
\text { of } \mathrm{HH}\end{array}$ & Income & Total \\
\hline $1965-66$ & 0.1 & 0.2 & -0.4 & -0.1 & 0.0 & -0.1 & 0.1 & -0.1 \\
\hline 1966-67 & 0.1 & 0.0 & 0.0 & 0.0 & 0.0 & 0.0 & 0.3 & 0.4 \\
\hline 1967-68 & 0.2 & 0.1 & -0.1 & 0.0 & 0.0 & 0.0 & 0.0 & 0.2 \\
\hline 1968-69 & -0.1 & -1.0 & 0.5 & 0.0 & 0.6 & -0.1 & 0.0 & -0.1 \\
\hline 1969-70 & 0.2 & -0.1 & -0.1 & 0.1 & -0.5 & 0.0 & 0.2 & -0.1 \\
\hline 1970-71 & 0.3 & 0.0 & -0.1 & -0.1 & -0.2 & 0.0 & -0.1 & -0.2 \\
\hline $1971-72$ & 0.3 & 0.7 & -0.4 & 0.0 & 0.0 & 0.0 & 0.0 & 0.5 \\
\hline $1972-73$ & 0.0 & 0.0 & 0.0 & 0.0 & 0.1 & 0.0 & -0.1 & -0.1 \\
\hline 1973-74 & -1.5 & 0.3 & 0.0 & 0.3 & 0.2 & 0.0 & 0.0 & -0.7 \\
\hline $1974-75$ & 0.9 & 0.0 & -0.3 & -0.3 & -0.1 & 0.1 & 0.0 & 0.3 \\
\hline $1975-76$ & 0.0 & 0.9 & -0.6 & 0.0 & -0.1 & 0.0 & -0.1 & 0.2 \\
\hline 1976-77 & 0.3 & -0.2 & 0.3 & 0.0 & 0.0 & 0.0 & -0.1 & 0.3 \\
\hline $1977-78$ & 0.5 & 0.0 & 0.0 & 0.0 & 0.0 & 0.0 & -0.1 & 0.3 \\
\hline 1978-79 & 0.0 & -0.3 & 0.1 & 0.0 & 0.0 & -0.1 & 0.0 & -0.3 \\
\hline 1979-80 & 0.0 & 0.6 & -0.2 & 0.0 & 0.0 & 0.0 & 0.0 & 0.4 \\
\hline 1980-81 & 0.0 & 0.3 & -0.1 & 0.0 & 0.0 & 0.0 & -0.1 & 0.1 \\
\hline $1981-82$ & 0.2 & -0.1 & 0.1 & 0.0 & -0.1 & 0.0 & 0.0 & 0.1 \\
\hline $1982-83$ & 0.3 & -0.6 & 0.3 & 0.0 & -0.1 & 0.1 & -0.1 & -0.1 \\
\hline 1983-84 & 0.3 & 0.4 & -0.2 & 0.0 & 0.0 & 0.0 & 0.0 & 0.4 \\
\hline 1984-85 & 0.1 & 0.3 & -0.7 & 0.1 & 0.0 & 0.0 & 0.0 & -0.1 \\
\hline $1985-86$ & 0.2 & 0.0 & 0.0 & 0.0 & 0.0 & 0.0 & 0.0 & 0.3 \\
\hline 1986-87 & 0.1 & 0.0 & -0.2 & 0.0 & 0.0 & 0.0 & -0.1 & -0.2 \\
\hline $1987-88$ & 0.0 & 0.0 & 0.0 & 0.0 & 0.0 & 0.0 & 0.0 & 0.0 \\
\hline 1988-89 & 0.7 & 0.6 & -0.4 & 0.0 & -0.1 & 0.0 & 0.0 & 0.9 \\
\hline $1989-90$ & 0.3 & -0.2 & 0.1 & 0.0 & 0.0 & 0.0 & -0.1 & -0.1 \\
\hline 1990-91 & -0.3 & -0.3 & 0.2 & 0.0 & 0.0 & 0.0 & 0.0 & -0.5 \\
\hline 1991-92 & -0.2 & -0.3 & 0.2 & 0.0 & 0.0 & 0.1 & -0.1 & -0.4 \\
\hline 1992-93 & 0.4 & 0.0 & 0.0 & -0.2 & 0.0 & 0.0 & 0.0 & 0.2 \\
\hline 1993-94 & -0.6 & 1.8 & -1.1 & 0.0 & 0.1 & 0.0 & -0.2 & 0.0 \\
\hline 1994-95 & 0.0 & 0.1 & -0.1 & 0.0 & 0.0 & 0.1 & 0.0 & 0.2 \\
\hline $1995-96$ & 0.2 & 0.2 & -0.2 & -0.1 & 0.0 & 0.0 & 0.1 & 0.2 \\
\hline $1996-97$ & 0.0 & 0.4 & -0.3 & 0.0 & 0.0 & 0.0 & 0.0 & 0.1 \\
\hline $1997-98$ & 0.6 & -0.9 & 0.6 & 0.0 & 0.0 & 0.2 & 0.0 & 0.4 \\
\hline 1998-99 & 4.9 & -22.2 & 6.4 & -0.1 & 1.8 & 9.3 & -0.2 & -0.1 \\
\hline 1999-00 & 0.1 & 0.7 & -0.4 & 0.0 & 0.0 & 0.0 & 0.0 & 0.4 \\
\hline 2000-01 & -0.1 & -0.2 & 0.3 & 0.0 & 0.0 & 0.0 & 0.0 & -0.2 \\
\hline 2001-02 & -0.2 & -0.1 & 0.0 & 0.0 & 0.0 & 0.0 & 0.0 & -0.2 \\
\hline $2002-03$ & 0.6 & -0.3 & 0.1 & 0.0 & 0.0 & 0.0 & 0.0 & 0.3 \\
\hline 2003-04 & 0.3 & -1.5 & 1.1 & 0.0 & -0.1 & 0.0 & 0.0 & -0.2 \\
\hline 2004-05 & -0.1 & -0.7 & 0.7 & 0.0 & 0.0 & 0.0 & 0.1 & 0.0 \\
\hline 2005-06 & 0.2 & -0.9 & 0.7 & 0.0 & 0.0 & 0.0 & -0.1 & -0.2 \\
\hline Total & 9.0 & -22.2 & 6.1 & -0.7 & 1.6 & 9.3 & -0.6 & 2.4 \\
\hline
\end{tabular}


TABLE A 8

MALES COEFFICIENTS, PROBIT DECOMPOSITION

\begin{tabular}{|c|c|c|c|c|c|c|c|c|}
\hline & Education & Age & $\begin{array}{c}\text { Age } \\
\text { Squared }\end{array}$ & $\begin{array}{c}\text { Children } \\
\text { less } \\
\text { than } 6\end{array}$ & $\begin{array}{c}\text { Children } \\
6 \text { to } 18\end{array}$ & $\begin{array}{l}\text { Head } \\
\text { of } \mathrm{HH}\end{array}$ & Income & Total \\
\hline $1965-66$ & 0.0 & 4.0 & -2.0 & 0.0 & -0.1 & -0.2 & 0.0 & 1.7 \\
\hline $1966-67$ & 0.0 & 0.3 & -0.1 & 0.0 & 0.0 & 0.0 & 0.0 & 0.2 \\
\hline $1967-68$ & -0.6 & -0.9 & 0.5 & 0.2 & 0.2 & -1.1 & 0.0 & -1.7 \\
\hline 1968-69 & -0.1 & 1.7 & -0.7 & 0.0 & 0.0 & 0.0 & 0.0 & 1.0 \\
\hline $1969-70$ & -0.2 & -4.7 & 2.3 & -0.4 & -0.1 & 1.0 & 0.2 & -1.8 \\
\hline $1970-71$ & -0.2 & 3.1 & -1.5 & 0.0 & 0.0 & -0.2 & 0.0 & 1.2 \\
\hline $1971-72$ & 0.1 & -1.5 & 0.8 & 0.0 & 0.0 & -0.2 & 0.0 & -0.8 \\
\hline $1972-73$ & -0.2 & -1.5 & 0.6 & -0.1 & 0.0 & 0.3 & 0.0 & -0.9 \\
\hline 1973-74 & -0.2 & 1.7 & -0.6 & 0.0 & -0.1 & -0.2 & 0.0 & 0.7 \\
\hline $1974-75$ & 0.0 & -1.3 & 0.6 & 0.0 & 0.0 & 0.0 & 0.0 & -0.8 \\
\hline $1975-76$ & 0.1 & -4.1 & 2.0 & 0.0 & 0.1 & 0.1 & 0.0 & -1.9 \\
\hline $1976-77$ & -0.3 & 5.2 & -2.5 & 0.0 & -0.1 & 0.3 & 0.0 & 2.7 \\
\hline $1977-78$ & 0.4 & -1.3 & 0.5 & 0.1 & 0.2 & -1.3 & -0.2 & -1.6 \\
\hline $1978-79$ & 0.0 & -4.4 & 0.8 & 0.3 & -0.6 & 1.9 & 0.2 & -1.7 \\
\hline 1979-80 & 0.1 & -0.3 & 0.1 & 0.0 & 0.0 & -0.2 & 0.0 & -0.4 \\
\hline $1980-81$ & 0.2 & 3.0 & -1.8 & -0.1 & -0.1 & 0.1 & 0.0 & 1.2 \\
\hline $1981-82$ & 0.0 & 0.1 & 0.0 & 0.0 & 0.0 & 0.0 & 0.0 & 0.1 \\
\hline $1982-83$ & -2.1 & 1.9 & -2.2 & -0.3 & 0.3 & 0.7 & -0.1 & -1.8 \\
\hline 1983-84 & 0.0 & -0.5 & 0.2 & 0.0 & 0.0 & 0.0 & 0.0 & -0.2 \\
\hline $1984-85$ & -1.7 & 15.8 & -9.1 & -0.6 & 0.1 & -1.4 & -1.0 & 2.2 \\
\hline $1985-86$ & -0.1 & 0.6 & -0.5 & 0.0 & 0.0 & -0.1 & -0.1 & -0.2 \\
\hline $1986-87$ & -0.3 & 0.8 & -0.8 & -0.1 & 0.0 & 0.1 & -0.1 & -0.3 \\
\hline $1987-88$ & -0.2 & -5.6 & 2.7 & 0.0 & 0.0 & -0.1 & -0.1 & -3.3 \\
\hline 1988-89 & 1.4 & 4.4 & -2.9 & 0.3 & -0.3 & 0.6 & -0.2 & 3.3 \\
\hline $1989-90$ & 2.5 & 2.4 & -2.1 & -0.1 & -1.2 & -0.9 & -0.2 & 0.4 \\
\hline $1990-91$ & -0.3 & -1.8 & 0.7 & 0.0 & -0.1 & 0.4 & 0.2 & -0.9 \\
\hline $1991-92$ & 0.0 & 2.1 & -0.9 & 0.0 & 0.0 & -0.2 & 0.0 & 1.0 \\
\hline $1992-93$ & -0.3 & 3.6 & -1.7 & 0.2 & 0.0 & 0.0 & -0.2 & 1.6 \\
\hline 1993-94 & 0.3 & -2.2 & 1.0 & 0.0 & -0.1 & 0.1 & -0.2 & -1.0 \\
\hline 1994-95 & -0.2 & 1.2 & -0.7 & 0.0 & 0.1 & 0.1 & 0.1 & 0.5 \\
\hline 1995-96 & 0.1 & 0.0 & 0.0 & 0.0 & 0.0 & 0.0 & 0.0 & 0.1 \\
\hline $1996-97$ & 0.2 & -0.9 & 0.4 & 0.0 & 0.0 & 0.1 & 0.0 & -0.3 \\
\hline 1997-98 & -0.2 & -4.8 & 2.2 & 0.0 & 0.0 & 0.6 & 0.0 & -2.2 \\
\hline 1998-99 & -0.1 & -1.2 & 0.5 & 0.1 & 0.0 & 0.3 & 0.0 & -0.5 \\
\hline 1999-00 & -0.1 & 6.9 & -5.4 & 0.3 & -0.5 & 0.5 & -0.3 & 1.5 \\
\hline $2000-01$ & -0.2 & 3.4 & -2.0 & 0.0 & 0.0 & 0.0 & -0.1 & 1.2 \\
\hline 2001-02 & 0.3 & -4.4 & 1.7 & 0.0 & 0.1 & 1.3 & 0.3 & -0.6 \\
\hline 2002-03 & 0.0 & 1.4 & -0.7 & 0.0 & 0.0 & 0.1 & 0.0 & 0.8 \\
\hline 2003-04 & 0.6 & -3.9 & -0.4 & 0.0 & 0.0 & 0.1 & -0.4 & -4.1 \\
\hline 2004-05 & 0.2 & 1.1 & 0.5 & 0.1 & 0.4 & -0.4 & -0.1 & 1.7 \\
\hline 2005-06 & 1.4 & -1.8 & 1.0 & 0.0 & -0.2 & 0.3 & -0.1 & 0.7 \\
\hline Total & 0.5 & 17.7 & -19.9 & -0.2 & -2.0 & 2.5 & -2.3 & -3.6 \\
\hline
\end{tabular}


TABLE A9

FEMALES MULTINOMAIL PROBIT DECOMPOSITION

\begin{tabular}{|c|c|c|c|c|}
\hline & Quantities & Coefficients & $\mathrm{Q}+\mathrm{P}$ & Actual Change \\
\hline $1965-66$ & -0.2 & -3.7 & -3.9 & -3.9 \\
\hline $1966-67$ & -0.9 & 4.0 & 3.1 & 2.9 \\
\hline $1967-68$ & -0.1 & -2.9 & -3.0 & -2.6 \\
\hline $1968-69$ & -1.6 & 0.7 & -0.9 & -1.2 \\
\hline $1969-70$ & 1.5 & 4.9 & 6.4 & 6.4 \\
\hline $1970-71$ & 1.8 & -2.4 & -0.6 & -0.9 \\
\hline $1971-72$ & 0.0 & 1.3 & 1.2 & 0.8 \\
\hline $1972-73$ & 0.7 & -1.4 & -0.7 & -0.9 \\
\hline $1973-74$ & -0.9 & -4.2 & -5.1 & -7.7 \\
\hline $1974-75$ & 2.4 & 2.7 & 5.0 & 7.5 \\
\hline $1975-76$ & 1.6 & -1.8 & -0.2 & -0.1 \\
\hline $1976-77$ & 2.0 & 1.8 & 3.8 & 5.0 \\
\hline $1977-78$ & -0.6 & 0.2 & -0.4 & -0.8 \\
\hline $1978-79$ & 1.2 & -2.7 & -1.5 & -2.0 \\
\hline $1979-80$ & 1.1 & 0.6 & 1.7 & 1.9 \\
\hline $1980-81$ & -0.4 & -1.3 & -1.7 & -1.9 \\
\hline $1981-82$ & 1.8 & 1.1 & 2.9 & 3.8 \\
\hline $1982-83$ & 1.1 & 1.9 & 3.0 & 3.6 \\
\hline $1983-84$ & 0.6 & -1.5 & -1.0 & -1.2 \\
\hline $1984-85$ & -0.1 & 1.3 & 1.2 & 1.4 \\
\hline $1985-86$ & 0.3 & -0.6 & -0.3 & -0.5 \\
\hline $1986-87$ & 0.5 & -0.6 & -0.1 & -0.2 \\
\hline $1987-88$ & -0.6 & -1.8 & -2.4 & -2.9 \\
\hline $1988-89$ & 1.4 & 0.9 & 2.2 & 2.4 \\
\hline $1989-90$ & 0.4 & 0.5 & 0.9 & 1.2 \\
\hline $1990-91$ & -0.3 & -2.2 & -2.5 & -2.8 \\
\hline 1991-92 & 0.3 & 2.2 & 2.5 & 2.3 \\
\hline $1992-93$ & -0.4 & 2.6 & 2.1 & 2.3 \\
\hline 1993-94 & 1.2 & -0.4 & 0.8 & 0.5 \\
\hline 1994-95 & -0.9 & 0.7 & -0.2 & -0.2 \\
\hline $1995-96$ & 0.8 & -0.2 & 0.6 & 0.4 \\
\hline $1996-97$ & 0.1 & -0.3 & -0.2 & -0.3 \\
\hline $1997-98$ & 1.3 & -3.4 & -2.1 & -2.0 \\
\hline 1998-99 & -1.0 & -1.1 & -2.1 & -2.6 \\
\hline 1999-00 & 1.0 & 2.0 & 3.0 & 3.7 \\
\hline $2000-01$ & -0.4 & -2.5 & -2.8 & -3.6 \\
\hline 2001-02 & -0.3 & 0.1 & -0.2 & -0.1 \\
\hline $2002-03$ & 0.2 & 0.2 & 0.4 & 0.9 \\
\hline 2003-04 & 0.2 & 1.0 & 1.2 & 1.2 \\
\hline 2004-05 & -0.3 & 1.3 & 1.0 & 0.2 \\
\hline $2005-06$ & 0.3 & -4.9 & -4.6 & -3.7 \\
\hline Total & 14.6 & -8.0 & 6.6 & 6.4 \\
\hline
\end{tabular}


TABLE A10

MALES MULTINOMAIL PROBIT DECOMPOSITION

\begin{tabular}{|c|c|c|c|c|}
\hline & Quantities & Coefficients & $\mathrm{Q}+\mathrm{P}$ & Actual Change \\
\hline $1965-66$ & -0.1 & 1.7 & 1.7 & 1.6 \\
\hline $1966-67$ & 0.4 & 0.3 & 0.6 & 0.6 \\
\hline $1967-68$ & 0.0 & -1.5 & -1.5 & -1.5 \\
\hline $1968-69$ & 0.0 & 0.7 & 0.7 & 0.9 \\
\hline $1969-70$ & -0.3 & -1.3 & -1.6 & -1.9 \\
\hline $1970-71$ & -0.4 & 1.2 & 0.8 & 1.0 \\
\hline $1971-72$ & 0.3 & -0.5 & -0.3 & -0.3 \\
\hline $1972-73$ & 0.0 & -0.9 & -1.0 & -1.0 \\
\hline $1973-74$ & -0.2 & 0.0 & -0.2 & 0.0 \\
\hline $1974-75$ & 0.7 & -1.1 & -0.4 & -0.5 \\
\hline $1975-76$ & 0.4 & -1.8 & -1.4 & -1.7 \\
\hline 1976-77 & 0.1 & 2.5 & 2.6 & 3.0 \\
\hline $1977-78$ & 0.2 & -1.3 & -1.1 & -1.3 \\
\hline 1978-79 & -0.4 & -1.2 & -1.6 & -2.0 \\
\hline $1979-80$ & 0.5 & -0.5 & 0.0 & -0.1 \\
\hline $1980-81$ & 0.4 & 0.8 & 1.2 & 1.4 \\
\hline $1981-82$ & 0.1 & 0.1 & 0.1 & 0.2 \\
\hline $1982-83$ & 0.2 & -1.6 & -1.4 & -1.9 \\
\hline $1983-84$ & 0.0 & 0.1 & 0.1 & 0.2 \\
\hline $1984-85$ & -0.1 & 1.6 & 1.5 & 2.0 \\
\hline $1985-86$ & 0.4 & -0.2 & 0.1 & 0.1 \\
\hline $1986-87$ & 0.1 & -0.5 & -0.4 & -0.5 \\
\hline $1987-88$ & -0.1 & -2.6 & -2.8 & -3.3 \\
\hline $1988-89$ & 0.6 & 2.8 & 3.4 & 4.1 \\
\hline $1989-90$ & 0.1 & 0.3 & 0.4 & 0.3 \\
\hline 1990-91 & -0.4 & -0.9 & -1.3 & -1.4 \\
\hline $1991-92$ & -0.3 & 0.9 & 0.6 & 0.6 \\
\hline $1992-93$ & 0.2 & 1.4 & 1.6 & 1.8 \\
\hline 1993-94 & 0.1 & -1.0 & -0.8 & -1.0 \\
\hline 1994-95 & 0.5 & 0.3 & 0.9 & 0.7 \\
\hline $1995-96$ & 0.4 & -0.2 & 0.2 & 0.3 \\
\hline 1996-97 & 0.2 & -0.4 & -0.1 & -0.2 \\
\hline $1997-98$ & 0.4 & -1.9 & -1.5 & -1.8 \\
\hline 1998-99 & 0.3 & -0.6 & -0.3 & -0.5 \\
\hline 1999-00 & 0.4 & 0.9 & 1.3 & 1.8 \\
\hline 2000-01 & 0.1 & 0.7 & 0.7 & 1.0 \\
\hline $2001-02$ & 0.0 & -0.6 & -0.6 & -0.9 \\
\hline 2002-03 & 0.5 & 0.4 & 0.9 & 1.1 \\
\hline 2003-04 & -0.1 & -3.5 & -3.5 & -4.3 \\
\hline 2004-05 & -0.2 & 1.6 & 1.4 & 1.6 \\
\hline 2005-06 & 0.3 & 0.3 & 0.6 & 0.6 \\
\hline Total & 5.2 & -5.6 & -0.4 & -1.2 \\
\hline
\end{tabular}


TABLE A11

FEMALES QUANTITIES, MULTINOMIAL PROBIT DECOMPOSITION

\begin{tabular}{|c|c|c|c|c|c|c|c|c|}
\hline & Education & Age & $\begin{array}{c}\text { Age } \\
\text { Squared }\end{array}$ & $\begin{array}{c}\text { Children } \\
\text { less } \\
\text { than } 6\end{array}$ & $\begin{array}{c}\text { Children } \\
6 \text { to } 18\end{array}$ & $\begin{array}{l}\text { Head } \\
\text { of } \mathrm{HH}\end{array}$ & Income & Total \\
\hline $1965-66$ & -0.2 & 0.2 & -0.1 & -0.1 & 0.0 & -0.1 & 0.0 & -0.2 \\
\hline 1966-67 & -0.7 & -0.3 & 0.2 & 0.0 & 0.2 & -0.1 & -0.1 & -0.9 \\
\hline $1967-68$ & -0.2 & 0.2 & -0.1 & 0.0 & 0.0 & 0.0 & 0.0 & -0.1 \\
\hline 1968-69 & -0.1 & 0.2 & 0.0 & -0.1 & -1.4 & -0.1 & -0.2 & -1.6 \\
\hline $1969-70$ & 1.0 & -0.4 & 0.2 & 0.2 & 0.2 & 0.0 & 0.4 & 1.5 \\
\hline $1970-71$ & 1.1 & 0.0 & 0.1 & 0.0 & 0.0 & 0.0 & 0.5 & 1.8 \\
\hline $1971-72$ & 0.0 & 0.0 & 0.0 & 0.0 & 0.0 & 0.0 & 0.0 & 0.0 \\
\hline $1972-73$ & 0.6 & 0.0 & 0.0 & 0.0 & 0.3 & 0.0 & -0.3 & 0.7 \\
\hline $1973-74$ & -0.7 & -0.1 & 0.0 & 0.0 & -0.2 & 0.0 & 0.0 & -0.9 \\
\hline $1974-75$ & 1.6 & 0.0 & 0.1 & 0.0 & 0.7 & 0.1 & 0.0 & 2.4 \\
\hline $1975-76$ & 1.1 & 0.1 & 0.3 & 0.1 & 0.0 & 0.0 & 0.1 & 1.6 \\
\hline 1976-77 & 1.4 & 0.0 & 0.1 & 0.0 & 0.0 & 0.0 & 0.5 & 2.0 \\
\hline $1977-78$ & -1.0 & 1.3 & -1.7 & 0.1 & -0.2 & 0.0 & 0.8 & -0.6 \\
\hline 1978-79 & 0.6 & 0.0 & 0.0 & 0.0 & 0.1 & 0.1 & 0.4 & 1.2 \\
\hline $1979-80$ & 0.3 & 0.8 & -0.4 & -0.1 & 0.5 & 0.0 & 0.0 & 1.1 \\
\hline $1980-81$ & -0.6 & 0.3 & 0.1 & 0.0 & 0.2 & 0.0 & -0.4 & -0.4 \\
\hline $1981-82$ & 1.5 & -0.1 & -0.1 & 0.2 & 0.3 & 0.0 & 0.0 & 1.8 \\
\hline $1982-83$ & 5.5 & -1.7 & 9.0 & 0.4 & -1.0 & -0.3 & -10.8 & 1.1 \\
\hline $1983-84$ & 0.3 & 0.8 & -0.5 & 0.0 & 0.1 & 0.0 & 0.0 & 0.6 \\
\hline $1984-85$ & -0.4 & -1.3 & -0.2 & 0.3 & 1.0 & 0.0 & 0.5 & -0.1 \\
\hline $1985-86$ & -0.8 & 2.3 & -1.2 & 0.0 & 0.0 & 0.1 & 0.0 & 0.3 \\
\hline $1986-87$ & 0.3 & 0.0 & 0.1 & 0.0 & 0.1 & 0.0 & 0.0 & 0.5 \\
\hline $1987-88$ & -0.6 & 0.0 & 0.0 & 0.0 & 0.0 & 0.0 & 0.1 & -0.6 \\
\hline $1988-89$ & 1.3 & 0.0 & 0.0 & 0.0 & 0.2 & 0.0 & -0.1 & 1.4 \\
\hline $1989-90$ & 0.0 & 0.1 & 0.0 & 0.0 & 0.1 & 0.1 & 0.1 & 0.4 \\
\hline $1990-91$ & -0.3 & 0.0 & 0.0 & 0.0 & 0.0 & 0.0 & 0.0 & -0.3 \\
\hline $1991-92$ & -0.7 & 0.6 & 0.0 & 0.2 & 0.3 & 0.1 & -0.2 & 0.3 \\
\hline $1992-93$ & -0.3 & 1.3 & -0.5 & 0.0 & 0.0 & 0.0 & -1.0 & -0.4 \\
\hline 1993-94 & 1.1 & 0.4 & -0.2 & 0.0 & 0.3 & 0.0 & -0.4 & 1.2 \\
\hline $1994-95$ & -0.7 & -0.6 & 0.4 & 0.0 & -0.1 & 0.0 & 0.1 & -0.9 \\
\hline $1995-96$ & 0.2 & 0.1 & 0.0 & 0.2 & -0.1 & 0.1 & 0.3 & 0.8 \\
\hline $1996-97$ & 0.2 & -0.1 & 0.0 & 0.0 & 0.0 & 0.0 & 0.0 & 0.1 \\
\hline $1997-98$ & 1.0 & 0.1 & 0.0 & 0.0 & 0.0 & 0.0 & 0.3 & 1.3 \\
\hline 1998-99 & -0.5 & -1.7 & 1.2 & 0.0 & 0.0 & 0.0 & -0.1 & -1.0 \\
\hline 1999-00 & 0.3 & 1.1 & -0.6 & 0.1 & 0.0 & 0.0 & 0.1 & 1.0 \\
\hline 2000-01 & -0.1 & -3.8 & 3.1 & 0.2 & 0.0 & 0.0 & 0.2 & -0.4 \\
\hline 2001-02 & -0.3 & 0.0 & 0.0 & 0.0 & 0.0 & 0.0 & 0.0 & -0.3 \\
\hline $2002-03$ & 0.2 & 0.0 & 0.0 & 0.0 & 0.0 & 0.0 & 0.0 & 0.2 \\
\hline 2003-04 & 0.6 & 0.1 & -0.4 & 0.0 & -0.1 & 0.0 & 0.0 & 0.2 \\
\hline 2004-05 & -0.2 & 0.7 & -0.9 & -0.1 & 0.3 & 0.0 & -0.1 & -0.3 \\
\hline 2005-06 & 0.4 & 1.7 & -2.0 & 0.0 & 0.0 & 0.1 & 0.2 & 0.3 \\
\hline Total & 12.3 & 2.3 & 5.9 & 1.7 & 1.6 & -0.1 & -9.1 & 14.6 \\
\hline
\end{tabular}


TABLE A12

FEMALES COEFFICIENTS, MULTINOMIAL PROBIT DECOMPOSITION

\begin{tabular}{|c|c|c|c|c|c|c|c|c|}
\hline & Education & Age & $\begin{array}{c}\text { Age } \\
\text { Squared }\end{array}$ & $\begin{array}{c}\text { Children } \\
\text { less } \\
\text { than } 6\end{array}$ & $\begin{array}{c}\text { Children } \\
6 \text { to } 18\end{array}$ & $\begin{array}{l}\text { Head } \\
\text { of HH }\end{array}$ & Income & Total \\
\hline $1965-66$ & -3.9 & 7.1 & -8.2 & -2.2 & 0.8 & 2.5 & 0.2 & -3.7 \\
\hline $1966-67$ & 0.5 & 6.4 & -2.6 & 0.1 & -0.1 & -0.2 & -0.1 & 4.0 \\
\hline 1967-68 & 0.5 & -6.7 & 3.4 & -0.1 & 0.2 & -0.1 & -0.1 & -2.9 \\
\hline $1968-69$ & 0.0 & 1.8 & -1.0 & 0.0 & -0.3 & 0.1 & 0.0 & 0.7 \\
\hline $1969-70$ & 0.8 & 7.7 & -4.0 & 0.0 & 0.0 & 0.3 & 0.1 & 4.9 \\
\hline $1970-71$ & -1.6 & 0.0 & -0.4 & 0.0 & 0.3 & 0.0 & -0.8 & -2.4 \\
\hline $1971-72$ & 0.3 & 1.1 & -0.5 & 0.0 & 0.1 & 0.1 & 0.2 & 1.3 \\
\hline $1972-73$ & 0.0 & -2.7 & 1.3 & 0.1 & 0.0 & -0.1 & 0.0 & -1.4 \\
\hline 1973-74 & 0.3 & -8.4 & 2.9 & 0.3 & 0.5 & 0.0 & 0.2 & -4.2 \\
\hline $1974-75$ & 0.5 & 3.8 & -1.8 & -0.1 & 0.1 & 0.1 & 0.1 & 2.7 \\
\hline $1975-76$ & 42.1 & -88.1 & 60.2 & -8.3 & 3.8 & -3.4 & -8.1 & -1.8 \\
\hline $1976-77$ & 0.6 & 2.1 & -1.0 & -0.1 & 0.2 & 0.0 & 0.0 & 1.8 \\
\hline $1977-78$ & 0.0 & 0.4 & -0.3 & 0.0 & 0.0 & 0.0 & 0.0 & 0.2 \\
\hline $1978-79$ & 0.7 & -5.6 & 2.2 & 0.1 & 0.1 & 0.2 & -0.4 & -2.7 \\
\hline $1979-80$ & -2.5 & 5.7 & -2.3 & -0.1 & -0.1 & -0.3 & 0.2 & 0.6 \\
\hline $1980-81$ & 0.6 & -1.0 & -0.6 & -0.4 & 0.1 & 0.2 & -0.1 & -1.3 \\
\hline $1981-82$ & 0.2 & 1.2 & -0.6 & 0.1 & 0.1 & 0.0 & 0.2 & 1.1 \\
\hline $1982-83$ & 0.4 & 2.7 & -1.3 & 0.0 & 0.0 & 0.0 & 0.1 & 1.9 \\
\hline $1983-84$ & 0.0 & -3.7 & 1.9 & 0.1 & 0.2 & 0.0 & 0.1 & -1.5 \\
\hline $1984-85$ & -33.4 & 98.0 & -54.4 & -3.7 & -2.1 & -1.2 & -1.9 & 1.3 \\
\hline $1985-86$ & 0.1 & -1.5 & 0.9 & 0.0 & 0.0 & 0.0 & 0.0 & -0.6 \\
\hline $1986-87$ & -0.2 & -0.4 & 0.1 & -0.1 & -0.1 & 0.0 & 0.1 & -0.6 \\
\hline $1987-88$ & 1.3 & -10.1 & 5.0 & 2.8 & 0.0 & -1.0 & 0.2 & -1.8 \\
\hline $1988-89$ & 0.1 & 1.6 & -0.7 & 0.0 & 0.0 & 0.0 & 0.0 & 0.9 \\
\hline $1989-90$ & -0.7 & 2.5 & -1.2 & 0.0 & 0.0 & -0.1 & 0.0 & 0.5 \\
\hline 1990-91 & -0.1 & -5.1 & 2.8 & 0.0 & 0.2 & 0.0 & 0.0 & -2.2 \\
\hline $1991-92$ & -0.4 & 4.4 & -2.0 & -0.2 & -0.2 & 0.1 & 0.5 & 2.2 \\
\hline $1992-93$ & -2.0 & 8.4 & -2.1 & -1.6 & 0.4 & -0.6 & 0.0 & 2.6 \\
\hline 1993-94 & 0.0 & -0.9 & 0.5 & 0.0 & 0.0 & 0.0 & -0.1 & -0.4 \\
\hline $1994-95$ & -0.1 & 1.8 & -0.9 & -0.1 & 0.0 & 0.0 & 0.0 & 0.7 \\
\hline $1995-96$ & 0.0 & -0.6 & 0.2 & 0.0 & 0.0 & 0.0 & 0.0 & -0.2 \\
\hline $1996-97$ & -0.1 & -0.4 & 0.2 & 0.0 & 0.0 & 0.0 & 0.0 & -0.3 \\
\hline $1997-98$ & 6.8 & -18.8 & 9.3 & -0.3 & 0.0 & 0.1 & -0.5 & -3.4 \\
\hline $1998-99$ & 0.9 & -5.0 & 2.8 & -0.1 & -0.1 & 0.0 & 0.4 & -1.1 \\
\hline 1999-00 & -0.7 & 7.1 & -4.2 & -0.1 & -0.2 & 0.1 & 0.0 & 2.0 \\
\hline 2000-01 & 0.3 & -6.2 & 3.4 & 0.1 & 0.3 & -0.1 & -0.2 & -2.5 \\
\hline 2001-02 & 0.0 & 0.1 & 0.0 & 0.0 & 0.0 & 0.0 & 0.0 & 0.1 \\
\hline $2002-03$ & 0.1 & 0.0 & 0.1 & 0.0 & 0.0 & 0.0 & 0.0 & 0.2 \\
\hline 2003-04 & 0.3 & 1.1 & -0.4 & 0.0 & 0.0 & 0.0 & 0.0 & 1.0 \\
\hline 2004-05 & -1.0 & 5.5 & -3.0 & 0.0 & 0.1 & -0.1 & -0.2 & 1.3 \\
\hline $2005-06$ & -0.5 & -9.2 & 4.3 & 0.0 & 0.1 & 0.2 & 0.2 & -4.9 \\
\hline Total & 10.2 & -3.8 & 7.7 & -13.6 & 4.1 & -3.0 & -9.6 & -8.0 \\
\hline
\end{tabular}


TABLE A13

MALES QUANTITIES, MULTINOMIAL PROBIT DECOMPOSITION

\begin{tabular}{|c|c|c|c|c|c|c|c|c|}
\hline & Education & Age & $\begin{array}{c}\text { Age } \\
\text { Squared }\end{array}$ & $\begin{array}{c}\text { Children } \\
\text { less } \\
\text { than } 6\end{array}$ & $\begin{array}{c}\text { Children } \\
6 \text { to } 18\end{array}$ & $\begin{array}{l}\text { Head } \\
\text { of } \mathrm{HH}\end{array}$ & Income & Total \\
\hline $1965-66$ & -0.1 & -0.1 & 0.1 & 0.0 & 0.0 & 0.0 & -0.1 & -0.1 \\
\hline $1966-67$ & 0.2 & 0.0 & 0.0 & 0.0 & 0.0 & 0.0 & 0.1 & 0.4 \\
\hline $1967-68$ & 0.0 & 0.0 & 0.0 & 0.0 & 0.0 & 0.0 & 0.0 & 0.0 \\
\hline 1968-69 & 0.0 & 0.0 & 0.0 & 0.0 & 0.0 & 0.0 & 0.0 & 0.0 \\
\hline $1969-70$ & -0.2 & 0.0 & 0.1 & -0.1 & 0.1 & 0.0 & -0.1 & -0.3 \\
\hline $1970-71$ & -0.5 & 0.0 & 0.1 & 0.0 & 0.0 & 0.0 & 0.0 & -0.4 \\
\hline $1971-72$ & 0.2 & 0.1 & 0.0 & 0.0 & 0.0 & 0.0 & 0.0 & 0.3 \\
\hline $1972-73$ & 0.0 & 0.0 & 0.0 & 0.0 & 0.0 & 0.0 & 0.0 & 0.0 \\
\hline 1973-74 & -0.2 & 0.0 & 0.0 & 0.0 & 0.0 & 0.0 & 0.0 & -0.2 \\
\hline $1974-75$ & 0.7 & 0.3 & -0.3 & 0.0 & 0.0 & 0.0 & 0.0 & 0.7 \\
\hline $1975-76$ & -0.2 & 0.9 & -0.1 & -0.1 & -0.1 & 0.1 & -0.2 & 0.4 \\
\hline $1976-77$ & 0.1 & -0.1 & 0.1 & 0.0 & 0.0 & 0.0 & 0.0 & 0.1 \\
\hline $1977-78$ & 0.2 & 0.0 & 0.0 & 0.0 & 0.0 & 0.0 & 0.0 & 0.2 \\
\hline 1978-79 & -1.2 & 1.9 & -0.5 & -0.8 & -0.3 & 0.9 & -0.4 & -0.4 \\
\hline $1979-80$ & 0.1 & -0.3 & 0.8 & 0.0 & 0.1 & -0.1 & 0.0 & 0.5 \\
\hline $1980-81$ & 0.3 & -0.3 & 1.3 & -0.3 & -0.1 & 0.0 & -0.5 & 0.4 \\
\hline $1981-82$ & 0.1 & 0.0 & 0.0 & 0.0 & 0.0 & 0.0 & 0.0 & 0.1 \\
\hline $1982-83$ & 0.6 & 0.0 & -0.1 & 0.0 & 0.0 & 0.1 & -0.5 & 0.2 \\
\hline $1983-84$ & 0.0 & 0.0 & 0.0 & 0.0 & 0.0 & 0.0 & 0.0 & 0.0 \\
\hline $1984-85$ & -0.2 & -0.5 & 0.6 & 0.0 & 0.0 & 0.0 & 0.0 & -0.1 \\
\hline $1985-86$ & 0.3 & -0.3 & 0.3 & 0.0 & 0.0 & 0.0 & 0.0 & 0.4 \\
\hline $1986-87$ & 0.1 & 0.1 & -0.2 & 0.0 & 0.0 & 0.0 & 0.1 & 0.1 \\
\hline $1987-88$ & -0.2 & 0.0 & 0.1 & 0.0 & 0.0 & 0.0 & 0.0 & -0.1 \\
\hline $1988-89$ & 0.6 & 0.0 & 0.0 & 0.0 & 0.0 & 0.0 & 0.0 & 0.6 \\
\hline $1989-90$ & 0.1 & 0.0 & 0.0 & 0.0 & 0.0 & 0.0 & 0.0 & 0.1 \\
\hline $1990-91$ & -0.3 & 0.1 & -0.1 & 0.0 & 0.0 & 0.0 & 0.0 & -0.4 \\
\hline $1991-92$ & -0.3 & 0.0 & 0.0 & 0.0 & 0.0 & 0.0 & 0.0 & -0.3 \\
\hline $1992-93$ & 0.2 & 0.0 & 0.0 & 0.0 & 0.0 & 0.0 & 0.0 & 0.2 \\
\hline 1993-94 & 0.2 & -0.1 & 0.0 & 0.0 & 0.0 & 0.0 & 0.0 & 0.1 \\
\hline $1994-95$ & 0.0 & 0.2 & -0.1 & 0.0 & 0.1 & 0.3 & 0.1 & 0.5 \\
\hline $1995-96$ & 0.3 & 0.1 & 0.0 & 0.0 & 0.0 & 0.0 & 0.2 & 0.4 \\
\hline $1996-97$ & -0.9 & 1.1 & -0.6 & -0.1 & 0.0 & 0.2 & 0.5 & 0.2 \\
\hline $1997-98$ & 0.5 & -0.2 & 0.1 & 0.0 & 0.0 & 0.1 & 0.0 & 0.4 \\
\hline 1998-99 & 0.5 & 0.3 & -0.8 & 0.0 & 0.1 & 0.2 & 0.0 & 0.3 \\
\hline 1999-00 & 0.2 & 0.1 & 0.1 & 0.0 & 0.0 & 0.0 & 0.0 & 0.4 \\
\hline 2000-01 & 0.1 & 0.0 & 0.0 & 0.0 & 0.0 & 0.0 & 0.0 & 0.1 \\
\hline 2001-02 & 0.0 & 0.0 & 0.0 & 0.0 & 0.0 & 0.0 & 0.0 & 0.0 \\
\hline 2002-03 & 0.6 & -0.1 & 0.1 & 0.0 & 0.0 & 0.0 & 0.0 & 0.5 \\
\hline 2003-04 & -0.1 & 0.1 & -0.1 & 0.0 & 0.0 & 0.0 & 0.0 & -0.1 \\
\hline 2004-05 & -0.3 & -0.4 & 0.4 & 0.0 & 0.0 & 0.0 & 0.1 & -0.2 \\
\hline $2005-06$ & 0.5 & -0.5 & 0.4 & 0.0 & 0.1 & 0.0 & -0.1 & 0.3 \\
\hline Total & 2.0 & 2.3 & 1.5 & -1.5 & -0.1 & 1.8 & -0.9 & 5.2 \\
\hline
\end{tabular}


TABLE A14

MALES COEFFICIENTS, MULTINOMIAL PROBIT DECOMPOSITION

\begin{tabular}{|c|c|c|c|c|c|c|c|c|}
\hline & Education & Age & $\begin{array}{c}\text { Age } \\
\text { Squared }\end{array}$ & $\begin{array}{c}\text { Children } \\
\text { less } \\
\text { than } 6\end{array}$ & $\begin{array}{c}\text { Children } \\
6 \text { to } 18\end{array}$ & $\begin{array}{l}\text { Head } \\
\text { of } \mathrm{HH}\end{array}$ & Income & Total \\
\hline $1965-66$ & -0.1 & 4.2 & -2.1 & 0.0 & -0.2 & -0.1 & 0.0 & 1.7 \\
\hline 1966-67 & 0.0 & 0.2 & -0.1 & 0.0 & 0.0 & 0.1 & 0.0 & 0.3 \\
\hline 1967-68 & -0.2 & -1.7 & 0.8 & 0.2 & 0.0 & -0.7 & -0.1 & -1.5 \\
\hline 1968-69 & -0.1 & 1.4 & -0.5 & 0.0 & 0.0 & 0.1 & 0.0 & 0.7 \\
\hline $1969-70$ & -0.3 & -6.2 & 2.9 & -1.0 & -0.1 & 2.8 & 0.5 & -1.3 \\
\hline 1970-71 & -0.3 & 3.0 & -1.4 & 0.1 & 0.0 & -0.2 & 0.0 & 1.2 \\
\hline $1971-72$ & 0.2 & -0.9 & 0.5 & 0.0 & -0.1 & -0.2 & -0.1 & -0.5 \\
\hline $1972-73$ & -0.1 & -1.6 & 0.7 & 0.0 & 0.0 & 0.1 & 0.0 & -0.9 \\
\hline 1973-74 & 0.0 & 0.0 & 0.0 & 0.0 & 0.0 & 0.0 & 0.0 & 0.0 \\
\hline 1974-75 & -0.1 & -1.7 & 0.8 & 0.0 & 0.0 & 0.0 & 0.0 & -1.1 \\
\hline $1975-76$ & -0.1 & -3.5 & 1.6 & 0.0 & 0.1 & 0.1 & 0.0 & -1.8 \\
\hline 1976-77 & -0.3 & 4.4 & -2.0 & -0.1 & -0.1 & 0.5 & 0.0 & 2.5 \\
\hline $1977-78$ & -0.1 & -2.7 & 1.3 & -0.1 & 0.0 & 0.3 & 0.0 & -1.3 \\
\hline 1978-79 & 0.0 & -2.2 & 1.2 & -0.1 & 0.0 & -0.1 & 0.0 & -1.2 \\
\hline 1979-80 & 0.2 & -0.7 & 0.4 & -0.1 & 0.0 & -0.2 & -0.1 & -0.5 \\
\hline 1980-81 & 0.3 & 1.7 & -1.0 & -0.1 & -0.1 & 0.1 & -0.1 & 0.8 \\
\hline $1981-82$ & 0.0 & 0.1 & 0.0 & 0.0 & 0.0 & 0.0 & 0.0 & 0.1 \\
\hline $1982-83$ & 0.8 & -5.4 & 3.6 & 0.0 & -0.2 & -0.4 & 0.0 & -1.6 \\
\hline 1983-84 & 0.0 & 0.3 & -0.1 & 0.0 & 0.0 & -0.1 & 0.0 & 0.1 \\
\hline 1984-85 & 0.1 & 1.4 & -0.5 & 0.1 & 0.1 & 0.2 & 0.2 & 1.6 \\
\hline $1985-86$ & -0.1 & -0.1 & 0.0 & 0.0 & 0.0 & 0.0 & 0.0 & -0.2 \\
\hline 1986-87 & 0.1 & -1.2 & 0.6 & 0.0 & 0.0 & 0.0 & 0.0 & -0.5 \\
\hline $1987-88$ & 0.0 & -5.4 & 3.0 & 0.1 & 0.1 & -0.4 & -0.1 & -2.6 \\
\hline 1988-89 & 2.2 & -1.9 & -9.2 & 1.5 & -0.8 & 10.8 & 0.2 & 2.8 \\
\hline $1989-90$ & 0.0 & 0.6 & -0.3 & 0.0 & 0.0 & 0.0 & 0.0 & 0.3 \\
\hline 1990-91 & -0.4 & -1.4 & 0.8 & 0.1 & -0.1 & 0.0 & 0.1 & -0.9 \\
\hline $1991-92$ & -0.1 & 2.3 & -0.9 & 0.0 & 0.1 & -0.3 & -0.1 & 0.9 \\
\hline 1992-93 & -0.9 & 4.9 & -2.3 & 0.2 & -0.1 & -0.1 & -0.1 & 1.4 \\
\hline 1993-94 & 0.0 & -1.6 & 0.7 & 0.0 & -0.1 & 0.1 & -0.1 & -1.0 \\
\hline 1994-95 & -0.1 & 0.8 & -0.4 & 0.0 & 0.0 & 0.0 & 0.0 & 0.3 \\
\hline $1995-96$ & -0.3 & 0.0 & 0.1 & 0.0 & 0.0 & 0.0 & 0.0 & -0.2 \\
\hline 1996-97 & 0.5 & -1.5 & 0.5 & 0.0 & -0.1 & 0.2 & 0.0 & -0.4 \\
\hline $1997-98$ & -0.7 & -2.7 & 1.2 & 0.0 & 0.0 & 0.3 & 0.0 & -1.9 \\
\hline $1998-99$ & -0.4 & -0.9 & 0.4 & 0.0 & 0.0 & 0.2 & 0.0 & -0.6 \\
\hline 1999-00 & 0.0 & 2.5 & -1.6 & 0.1 & -0.1 & 0.1 & -0.1 & 0.9 \\
\hline 2000-01 & 0.2 & 1.3 & -0.7 & 0.0 & -0.1 & 0.0 & -0.1 & 0.7 \\
\hline 2001-02 & 0.1 & -1.5 & 0.7 & 0.0 & 0.1 & 0.0 & 0.0 & -0.6 \\
\hline 2002-03 & 0.5 & -0.5 & 0.4 & 0.0 & 0.0 & 0.1 & 0.0 & 0.4 \\
\hline 2003-04 & -16.6 & 77.3 & -52.6 & 0.2 & -1.1 & -8.5 & -2.1 & -3.5 \\
\hline 2004-05 & -0.1 & 0.1 & 0.9 & 0.2 & 0.7 & -0.3 & 0.0 & 1.6 \\
\hline 2005-06 & 2.9 & -5.1 & 3.1 & -0.1 & -0.7 & 0.6 & -0.5 & 0.3 \\
\hline Total & -13.1 & 56.1 & -49.6 & 1.1 & -2.5 & 4.9 & -2.5 & -5.6 \\
\hline
\end{tabular}


